\title{
Diatremas da Formação Hilário nas minas do Seival, Bacia do Camaquã, sul do Brasil
}

\author{
Giuseppe B. DE TONI, Arceolinda L. S. MONTEIRO, Edna J. F. TUNGO, \\ Ludira P. J. SYANGEVE, Núria de Fátima M. de ASSIS, Rodrigo W. LOPES \& \\ Francisco M. W. TOGNOLI
}

Curso de Geologia, Escola Politécnica, Universidade do Vale do Rio dos Sinos (UNISINOS),

Av. Unisinos, 950, São Leopoldo, 93022-750, RS, Brazil (detoni.geo@gmail.com, giuseppebt@unisinos.br, arceomonteiro@gmail.com, ednatungo@gmail.com, lurapatricia2@gmail.com,nuriadeassis@gmail.com, rodrigo.winck.lopes@gmail.com,ftognoli@unisinos.br).

\begin{abstract}
Resumo. Duas estruturas circulares geminadas, de aproximadamente 1 km de diâmetro cada, ocorrem na porção sul da região das minas do Seival (Caçapava do Sul, RS), em rochas da Formação Hilário (Grupo Bom Jardim da Bacia do Camaquã). Com o objetivo de caracterizar estas feições, foi desenvolvido um trabalho de mapeamento geológico-estrutural com imagens de sensoriamento remoto, trabalho de campo, petrografia e análises gamaespectrométricas. Dentro das estruturas são descritas brechas piroclásticas formadas por blocos do andesito circundante, de até $1 \mathrm{~m}$ de comprimento. A matriz piroclástica da brecha é formada por litoclastos de andesito, cristaloclastos de plagioclásio e clinopiroxênio semelhantes aos fenocristais do andesito, e cinza vulcânica muito fina. Processos de fragmentação in situ em presença de fluidos são interpretados a partir de fraturas transgranulares e interclasto, dividindo fragmentos e cortando a matriz de forma curviplanar, com frequente preenchimento por calcita. A orientação de lineamentos estruturais e de planos de fraturas confirmam o trend regional NE - SW e ilustram o padrão localmente multi-direcional, característico das estruturas circulares. Dados gamaespectrométricos indicam o caráter shoshonítico dos andesitos (médias de $\mathrm{K}$ 4,4\%; U 4,4 ppm; Th 19,2 ppm; e contagem total $5070 \mathrm{cps}$ ), que contrastam com a assinatura das brechas piroclásticas (médias de K 1,7\%; U 3 ppm; Th 6,1 ppm; contagem total de 2252 cps), o que corrobora o contato mapeado, e permite a correlação geoquímica das brechas com as rochas vulcânicas da área de estudo. A integração destes dados permite interpretar as estruturas circulares como diatremas ou antigas chaminés vulcânicas.
\end{abstract}

Palavras-chave. estrutura circular; chaminé vulcânica; brecha piroclástica; mapeamento geológico; Grupo Bom Jardim

\begin{abstract}
Diatremes of HiLÁRIO Formation IN THE SEIVAL MINES, CAMAQUÃ BASIN, SOUTHERN BRAZIL. Two twinned circular structures of about $1 \mathrm{~km}$ diameter each are recognized in the southern portion of Seival Mine (Caçapava do Sul, RS, Brazil), in rocks of Hilário Formation (Bom Jardim Group, Camaquã Basin). The characterization of such features was developed through geological and structural mapping with remote sensing images, fieldwork, petrography and gammaspectrometric analysis. Pyroclastic breccia composed of up to $1 \mathrm{~m}$ length blocks of the surrounding andesite is described inside the circular structures. The pyroclastic matrix is composed of andesite lithoclasts, plagioclase and clinopyroxene crystaloclasts similar to the andesite phenocrysts and very fine-grained ash. Fluid-related in situ fragmentation processes are interpreted because of transgranular and interclast fractures, dividing fragments, crosscutting the matrix as curviplanar surfaces, and being frequently filled by carbonate. Structural lineaments and fracture planes orientation confirm the regional trend NE - SW and also illustrate the multi-directional local pattern, characteristic of the circular structures. Gammaspectrometric data indicate a shoshonitic character of the andesite (average K 4.4\%; U 4.4 ppm; Th 19.2 ppm; total count $5070 \mathrm{cps}$ ), that contrasts to the pyroclastic breccia signature (average $\mathrm{K} 1.7 \%$; U 3 ppm; Th 6.1 ppm; total count $2252 \mathrm{cps}$ ), which confirms the mapped contact, and led to the geochemical correlation with volcanic rocks from the study. Data integration allows interpreting such circular structures as diatremes or ancient volcanic chimneys.
\end{abstract}

Keywords. circular structure; volcanic chimney; pyroclastic breccia; geological mapping; Bom Jardim Group 


\section{Introdução}

Estruturas circulares expressas no relevo de uma dada região têm sua origem geralmente atribuída a processos magmáticos ou de impacto (e.g. Martins et al., 2016). Em sistemas magmáticos, estas estruturas são frequentemente interpretadas como diatremas (Jerram \& Petford, 2011; White \& Ross, 2011; Mundula et al., 2013) ou caldeiras vulcânicas (Cole et al., 2005; Acocella, 2007; Tratz \& Waichel, 2019), sendo ambas estruturas entendidas como extremos de um espectro contínuo de estruturas circulares formadas durante eventos vulcânicos com importante componente explosivo (Palladino et al., 2015).

Diatremas são condutos ou chaminés vulcânicas alongadas, com seção aproximadamente circular de até $1 \mathrm{~km}$ de diâmetro, preenchidos por uma mistura de material vulcânico e derivado das rochas atravessadas pelo diatrema (Green \& Short, 1971; Jerram \& Petford, 2011; Palladino et al., 2015). Segundo Green \& Short (1971), as chaminés são produzidas durante eventos explosivos, quando as fraturas na rocha encaixante são alargadas por gases formados por interação freato-magmática, causando sua fragmentação. Esse processo leva à fluidização da mistura gás-magma-rocha, que pode circular pela chaminé em expansão. A associação de diatremas com rochas vulcânicas máficas de composição mineral incomum, como kimberlitos ou lamprófiros, é uma característica distintiva (Green \& Short, 1971; Satian et al., 2009; Jerram \& Petford, 2011; Nasir et al., 2011). O termo maar é utilizado para descrever a expressão em superfície de sistemas maardiatrema recentes ou não-erodidos, geralmente uma pequena depressão vulcanogênica (e.g. Lorenz \& Kurszlaukis, 2006; White \& Ross, 2011; Graettinger, 2018).

No sul do Brasil e Uruguai, uma série de bacias vulcano-sedimentares de idade Ediacarana a Ordoviciana são reconhecidas ao longo do Cinturão Dom Feliciano (Fig. 1), registrando a evolução mais tardia deste orógeno (e.g. Almeida et al., 2010, 2012 e referências ali contidas). No estado do Rio Grande do Sul, sub-bacias correlacionadas a este sistema são coletivamente chamadas de Bacia do Camaquã (Fragoso Cesar et al., 2000; Paim et al., 2000, 2014; Wildner et al., 2002; Oliveira et al., 2014; entre outros). Independente de discussões sobre os ambientes tectônicos representados pelas sucessões preservadas, a importância da contribuição vulcânica para o preenchimento desta bacia é bem reconhecida ao longo de toda sua história (e.g. Ribeiro \& Fantinel, 1978; Paim et al., 2000, 2014; Wildner et al., 2002; Lima et al., 2007a; Borba et al., 2007, 2008; entre outros).

A relação genética entre as rochas vulcânicas efusivas e explosivas da Formação Hilário, de composição predominantemente intermediária, eas rochas plutônicas do Complexo Intrusivo Lavras do Sul, já é bem estabelecida desde a definição da Associação Shoshonítica Lavras do Sul, que abrange também a ocorrência de diversos termos hipoabissais, incluindo lamprófiros (Nardi \& Lima, 1985; 1988; Lima \& Nardi, 1998; Lima et al., 2007b; entre outros). 0 modelo mais recente assume que o sistema evoluiu através de um colapso de caldeira que culminou na justaposição entre as rochas plutônicas e vulcânicas (Gastal et al., 2015).

A existência de "antigos cones vulcânicos" relacionados à Formação Hilário (Grupo Bom Jardim) dispersos em distintos pontos da Bacia do Camaquã é mencionada por Ribeiro e Fantinel (1978), incluindo ocorrências "entre o Arroio do Seival e Lavras do Sul". Toniolo et al. (2007) documentam diversas estruturas (semi-) circulares nesta região a partir de fotointerpretação (Fig. 1C). Uma destas estruturas, a leste/nordeste de Lavras do Sul coincide com intrusões sub-vulcânicas tardias, de composição monzonítica (Liz et al., 2004; Müller et al., 2012). Na área das minas do Seival, Lopes et al. (2018) identificam rochas como aglomerado vulcânico, devido a predominância de blocos de grandes dimensões em relação ao lápili-tufo. Estas rochas são associadas a estruturas como falhas e fraturas, e coincidem espacialmente com duas destas estruturas circulares reportadas por Toniolo et al. (2007), uma na porção norte da região das minas, e outra a sul destas (Fig. 1C deste trabalho e fig. 5 de Lopes et al., 2018).

Com o objetivo de documentar a geologia 
de duas estruturas circulares geminadas (uma delas até então desconhecida) na Formação Hilário, Grupo Bom Jardim da Bacia do Camaquã, neste trabalho são sintetizados resultados de mapeamento geológico na porção sul da região de Minas do Seival. Estes resultados foram obtidos por um dos grupos de trabalho do chamado Projeto Seival-Lavras, desenvolvido no âmbito das atividades acadêmicas Exploração e Avaliação de Depósitos Minerais I e II do curso de graduação em Geologia da Universidade do Vale do Rio dos Sinos (UNISINOS), ministradas no ano de 2019. A integração de dados de campo e estruturais, com observações petrográficas e dados gamaespectrométricos, possibilitam a comparação geoquímica com as rochas vulcânicas da região e a interpretação da evolução geológica conjunta para a área de estudo, com decorrências para a compreensão da evolução geológica regional e do sistema plutono-vulcânico, hidrotermal e mineralizante da Associação Shoshonítica de Lavras do Sul.

\section{Métodos}

Os dados aqui integrados no mapeamento geológico da área de estudo incluem resultados obtidos com sensoriamento remoto, observações de campo, dados estruturais, gamaespectrometria e petrografia. 0 sensoriamento remoto foi baseado em fotografias aéreas e imagens de satélite do Google Earth ${ }^{\text {TM }}$, também utilizadas para confecção de anaglifos na escala 1:25.000. Essa análise permitiu delinear possíveis contatos litológicos, além do traçado de lineamentos e o reconhecimento de estruturas circulares, posteriormente checados durante trabalho de campo.

Duas etapas de campo somaram dez dias de trabalho, cujo principal resultado foi o mapa geológico em escala 1:25.000, apresentado em uma versão simplificada, exibindo os principais pontos descritos e discutidos neste trabalho (e.g. ponto SL-2012 é apresentado como 12). O mapa de pontos correspondente é disponibilizado como material suplementar (Apêndice 1). Além disso, dados estruturais foram coletados, assim como amostras representativas, descritas macro- e microscopicamente. Os resultados de campo serão apresentados na ordem lógica em que foram obtidos e integrados, constituindo uma seção geológica aproximadamente de leste para oeste na área de estudo. Dados gamaespectrométricos das principais rochas mapeadas também foram obtidos em campo, com tempo de aquisição de 3 minutos em cada medida, utilizando um gamaespectrômetro portátil, modelo RS-125 Super-SPEC, da Radiation Solutions INC, gentilmente disponibilizado pelo Laboratório de Sensoriamento Remoto e Cartografia Digital (LASERCA) da UNISINOS. Os dados gamaespectrométricos são utilizados para uma comparação com dados geoquímicos de rocha total da Formação Hilário, aflorantes na região das Minas do Seival (Lopes et al., 2014). Para tanto os dados gamaespectrométricos de $\mathrm{K} \%$ foram convertidos para $\mathrm{K}_{2} \mathrm{O} \%$ através de cálculo estequiométrico.

\section{Contexto geológico}

\section{1 Geologia regional}

O Cinturão Dom Feliciano é considerado a faixa móvel adjacente aos crátons Rio de La Plata e Luis Alves (Paleoproterozoico), além do Terreno Nico Perez (Arqueano - Mesoproterozoico), formado entre o início do Neoproterozoico e o Eo-Paleozoico, durante a amalgamação do Gondwana Ocidental (Fig. 1A - De Toni et al., 2020, entre outros). De forma simplificada, de oeste para leste, este cinturão compreende quatro domínios (Fig. 1B). O Bloco São Gabriel registra um ambiente de margem ativa com acresção de ofiolitos, magmatismo de arco de ilhas e/ ou continental e sedimentação sin-orogênica, exposto unicamente no oeste do Rio Grande do Sul (Philipp et al., 2018 apresenta uma revisão sobre a região). A Faixa de Dobramentos Tijucas (definida por Hasui et al., 1975) é um cinturão de dobras e cavalgamentos de antepaís onde predominam rochas supracrustais do Toniano a Ediacarano, incluindo sequências de baixo- a médio-grau metamórfico, e ocorrências locais do embasamento Paleoproterozoico aflorante em núcleos de antiformes (infra-estrutura). 


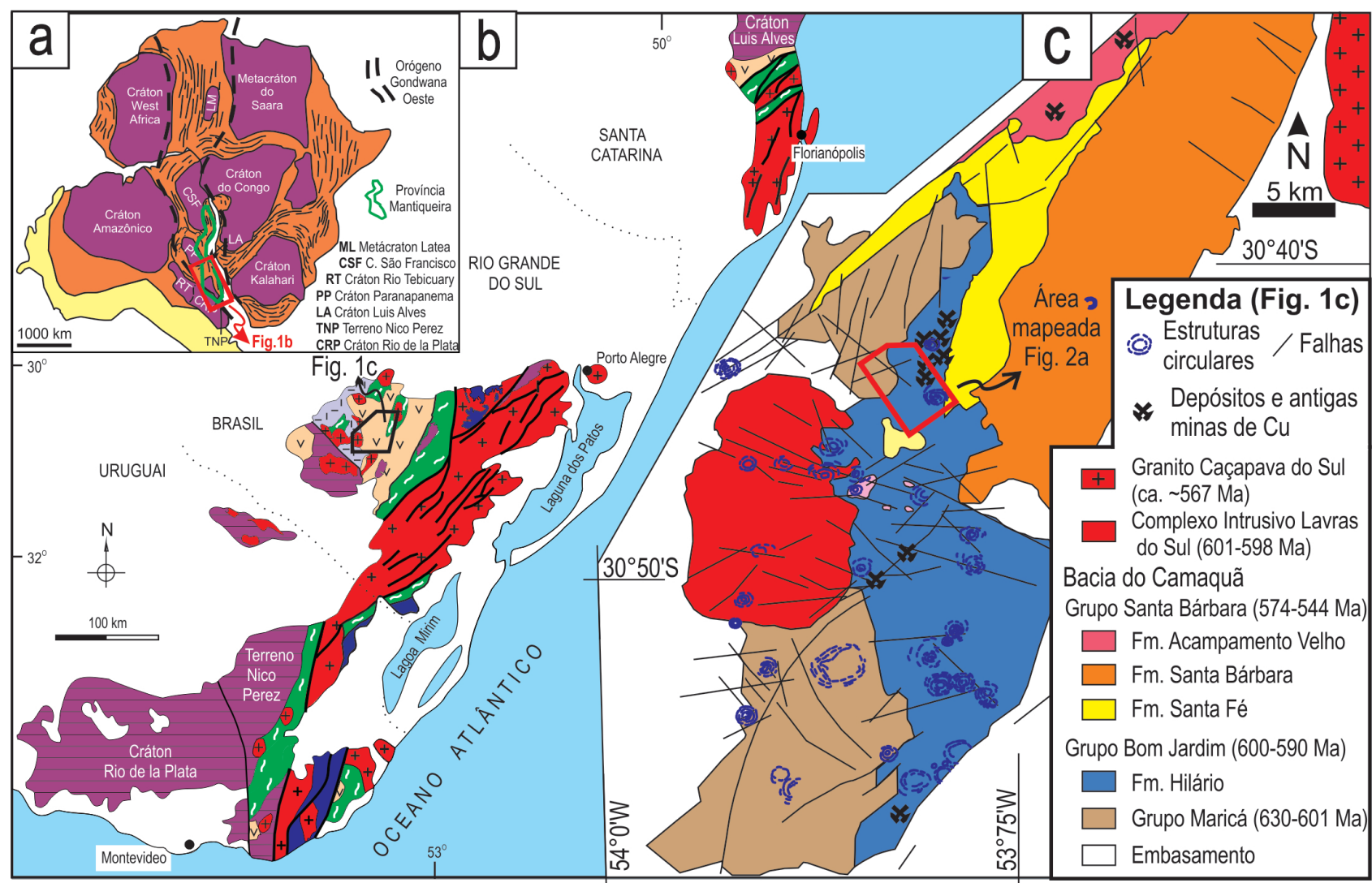

Legenda (Fig. 1b)

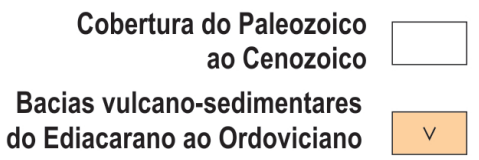

Magmatismo Granítico Pós-colisional Criogeniano a Ediacarano

Magmatismo de Arco Toniano a Criogeniano

Sequências metamórficas de baixoa médio-grau, Toniano a Ediacarano

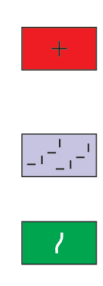

\section{Sequências metamórficas de alto-grau do Toniano \\ Sequências do
Arqueano ao Paleoproterozoico \\ Cinturão de Cisalhamento Sul-brasileiro}

Figura 1. Mapas geotectônicos e de localização da área de estudo. A) Esboço tectônico do Gondwana Oeste; B) Mapa geotectônico do Cinturão Dom Feliciano (modificado de Bitencourt \& Nardi, 2000; De Toni et al., 2020); C) Mapa da Bacia do Camaquã na região entre Lavras do Sul e Caçapava do Sul (RS), localizando a área do mapa geológico da figura 2 (modificado de Toniolo et al., 2007; Lopes et al., 2019).

Figure 1. Geotectonic and study area location maps. A) Tectonic sketch of Western Gondwana; B) Geotectonic map of Dom Feliciano Belt (modified from Bitencourt \& Nardi, 2000; De Toni et al., 2020); C) Camaquã Basin map in the region between Lavras do Sul and Caçapava do Sul (RS), locating the area of figure 2 (modified from Toniolo et al., 2007; Lopes et al., 2019).

Um terceiro domínio representa o além-país do cinturão, composto dominantemente de batólitos graníticos pós-colisionais, sin- a tardi-tectônicos, com pendentes de teto de sequências gnáissicas de alto grau que registram metamorfismo colisional sobre protólitos précolisionais (Bitencourt \& Nardi, 2000; Philipp et al., 2005; De Toni et al., 2020; entre outros). Tanto a Faixa de Dobramentos Tijucas quanto o domínio de batólitos graníticos afloram lado a lado por cerca de $1.200 \mathrm{~km}$, desde o sul do Uruguai até o litoral do estado de Santa Catarina. Ambos os domínios têm como embasamento rochas correlacionadas ao chamado Terreno Nico Perez, e são delimitados e estruturados internamente por zonas de cisalhamentos transpressivas enfeixadas no chamado Cinturão de Cisalhamento Sul-Brasileiro (Bitencourt \& Nardi, 2000). Um quarto domínio de sequências supracrustais ocorre localmente no extremo sul do Rio Grande do Sul e no litoral do leste uruguaio, a sudeste do Batólito Pelotas (e.g. Ramos et al., 2019; Abre et al., 2020). Sequências vulcanossedimentares tardi-orogênicas recobrem partes da Faixa de Dobramentos Tijucas e do Bloco São Gabriel, assim como o contato entre estes domínios. Estas sequências foram acumuladas em loci deposicionais que evoluíram de forma conjunta na chamada Bacia do Camaquã (Fragoso Cesar et al., 2000; Paim et al., 2000, 2014; dentre outros). 
A Bacia do Camaquã registra os processos tectônicos, magmáticos e sedimentares do período pós-colisional no ante-país deste cinturão orogênico (Fig. 1C). Quatro grandes sequências vulcanossedimentares são separadas por discordâncias angulares e erosivas, marcando pulsos tectônicos predominantemente extensionais (Fragoso Cesar et al., 2000; Paim et al., 2000; 2014; Almeida et al., 2010, 2012). De forma simplificada, a sequência estratigráfica desta bacia pode ser resumida como: Grupo Maricá (630 - 600 Ma), de ambiente predominantemente lacustre ou marinho e subordinadamente fluvial, com contribuição vulcânica; Grupo Bom Jardim (600 - 580 $\mathrm{Ma})$ com volumoso vulcanismo efusivo e explosivo de associação shoshonítica e sedimentação associada, correlacionado em tempo, espaço e gênese a granitoides intrusivos; Grupo Santa Bárbara (575 - 550 Ma) com importante sedimentação clástica imatura de conglomerados com proveniência vulcânica e plutônica, além de vulcanismo bi-modal alcalino; e Grupo Guaritas (550 - 470 Ma), com registro de ambiente desértico e fluvial e um último episódio de vulcanismo básico alcalino (baseado em Paim et al., 2000, 2014; Oliveira et tal., 2014; e referências ali contidas).

\subsection{O Vulcanismo Hilário e as Minas do Seival}

A Formação Hilário (Grupo Bom Jardim) é composta predominantemente por traquibasaltos e traquiandesitos de textura fina, tufos, lápili-tufos e aglomerados vulcânicos, além de rochas epiclásticas e intrusivas hipoabissais na forma de diques orientados predominantemente NE-SW (na região de Minas do Seival - Reischl, 1978; Nardi \& Lima, 1985; Lopes et al., 2014, 2018) e NW-SE (na região de Lavras do Sul - e.g. Liz et al., 2004; Müller et al., 2012; Gastal et al., 2015; entre outros). Estas rochas estão intimamente correlacionadas ao Complexo Intrusivo Lavras do Sul, na chamada Associação Shoshonítica de Lavras do Sul, em um contexto plutono-vulcânico relacionado ao magmatismo pós-colisional no ante-país do Cinturão Dom Feliciano (Nardi \& Lima, 1985; 1988; Lima \& Nardi, 1998; Gastal et al., 2015 e referências inclusas). No modelo proposto por Gastal et al. (2015), o posicionamento do Complexo Intrusivo Lavras do Sul ocorre em pulsos sucessivos, de forma relativamente tardia em relação ao vulcanismo da Formação Hilário, culminando com um colapso de caldeira que causa a justaposição das porções plutônica e vulcânica do sistema.

As rochas vulcânicas da região das Minas do Seival, tanto andesitos quanto lápili-tufos, assim como diques de andesito e monzonito, foram descritos inicialmente por Reischl (1978), e mais recentemente por Lopes et al. (2014, 2018, 2019) e Fontana et al. (2017; 2019), como pertencentes respectivamente às chamadas sequência 1 e sequência 2 do vulcanismo da Formação Hilário. As Minas do Seival compreendem seis minas e algumas ocorrências de Cu-Ag, sendo de norte para sul as minas Barita, João Dahne, Morcego, do Meio, Cruzeta e Alcides (Reischl, 1978; Lopes et al., 2014). Os trabalhos mais recentes desenvolvidos na área de estudo focaram na caracterização petrológica (Lopes et al., 2014) e nos processos de alteração hidrotermal e mineralização (Fontana et al., 2017, 2019; Lopes et al., 2018, 2019). O estudo desta associação do ponto de vista do hidrotermalismo e mineralização é notório, e indica a evolução de um sistema similar a um modelo pórfiroepitermal de alta latitude, com progressiva transição de contribuições magmáticas para meteóricas, de ambiente glacial (e.g. Bongiolo et al., 2011), no qual o enriquecimento em Cu (região de Minas do Seival) e Au (região de Lavras do Sul) é vinculado aos pulsos subvulcânicos pristinos tardios (Fontana et al., 2019; Lopes et al. 2019), incluindo magmas lamprofíricos (Lima et al., 2007b), durante o colapso da caldeira (e.g. Gastal et al., 2015).

Os minerais característicos do estágio magmático na área das Minas do Seival são andesina-labradorita e augita (Fontana et al., 2017; Lopes et al., 2019). A alteração hidrotermal foi dividida em dois episódios: propilitização e argílica intermediária. A propilitização ocorreu por ação de um fluido magmático a tardi-magmático e pode ser subdividida em duas etapas: uma de temperatura mais alta $\left(350\right.$ a $\left.250^{\circ} \mathrm{C}\right)$ caracterizada pela assembleia de clorita, quartzo, calcita e pirita com calcopirita, e pela albitização 
do plagioclásio; e uma etapa de temperatura mais baixa $\left(250\right.$ a $\left.150^{\circ} \mathrm{C}\right)$ caracterizada pela assembleia de clorita, interestratificado clorita/ esmectita, calcita, titanita, quartzo e hematita, com sulfetos ricos em cobre (bornita e calcocita). Assim, o enriquecimento de cobre foi associado ao estágio de propilitização, com a transformação de calcopirita em bornita e calcocita (Fontana et al., 2017, 2019). A alteração argílica intermediária é de temperatura ainda mais baixa $\left(<157^{\circ} \mathrm{C}\right)$ e ocorreu com uma influência maior de água meteórica. Esta alteração foi caracterizada pelas assembleias de esmectita e cristobalita (quartzo), e também de barita, calcita, hematita e quartzo (Fontana et al., 2017; Lopes et al., 2019). Malaquita e azurita ocorrem como produtos supergênicos $\left(<50^{\circ} \mathrm{C}\right)$ devido à oxidação dos minerais ricos em cobre.

\section{Resultados}

\subsection{Sensoriamento remoto e mapeamento geológico-estrutural}

O trabalho com anaglifos permitiu delimitar os principais contatos litológicos e estruturas, assim como inferir os litotipos aflorantes. Estes resultados, posteriormente verificados durante o mapeamento geológico, estão sintetizados no mapa geológico da figura 2A. Muitas das características discutidas a seguir podem ser observadas no anaglifo da figura 2B, o qual recobre a maior parte das litologias mapeadas, com destaque para as duas estruturas circulares.

A porção noroeste da área de estudo corresponde às rochas sedimentares siliciclásticas do Grupo Maricá, sendo o relevo moderadamente acidentado, com rede de drenagem e vegetação escassas. O limite do Grupo Maricá com as rochas da Formação Hilário é encoberto na área de estudo, mas expresso por lineamentos NE-SW e NW-SE que condicionam o Arroio Teixeira (afluente do Arroio Hilário).

A diversidade litológica da Formação Hilário reflete-se em importantes características geomorfológicas diagnósticas dos distintos litotipos mapeados. 0 andesito tem relevo relativamente mais arrasado em comparação com os equivalentes piroclásticos (e.g. lápili- tufo), e vegetação mais escassa, com raras árvores marcando lineamentos, muitos destes representando diques de composição andesítica a traquiandesítica que cortam a sequência vulcânica acamada (e.g. Lopes et al., 2014, 2018). O lápili-tufo apresenta uma vegetação mais abundante ("mata-parque"), que é característica diagnóstica quando comparada com as outras rochas da mesma unidade (Fig. 2B). A rede de drenagem é claramente condicionada pelas estruturas rúpteis da região, seguindo um padrão paralelo a sub-paralelo em relação aos lineamentos principais ENE-WSW, e secundariamente NNW-SSE.

As duas estruturas circulares estudadas ocorrem de forma geminada, dispostas lado-alado na direção E-W. Cada uma destas estruturas têm diâmetro médio de ca. $1 \mathrm{~km}$, coincidindo com as características típicas de diatremas (e.g. Palladino et al., 2015), e apresentam alongamento ligeiramente maior na direção NNW-SSE. A vegetação dentro das estruturas circulares é caracteristicamente escassa, do tipo campo aberto. A mata ciliar é restrita a algumas drenagens (aparentemente intermitentes), sendo presente principalmente na estrutura circular leste. A geomorfologia apresentada é semelhante à de duas crateras em forma de ferradura ou anfiteatro, ambas abertas para NNW, para onde fluem as drenagens axiais. O desnível da estrutura leste é de até $270 \mathrm{~m}$ na borda sudeste para 210 $m$ no seu centro. 0 divisor de águas entre elas tem 250 m de altitude na porção sul e desce para 220 m na porção norte, semelhante à borda oeste da estrutura oeste. 0 centro da estrutura circular oeste tem altitude de $200 \mathrm{~m}$.

A porção leste é a região mais alta da área mapeada (Fig. 2A e B), onde afloram as rochas conglomeráticas da Formação Santa Fé, do Grupo Santa Bárbara. Estas rochas apresentam nos anaglifos uma textura característica do seu acamamento, mergulhando em baixo ângulo para leste, dada por feições lineares caracterizadas pela vegetação e por exposições de rocha arenito-conglomerática em lajeados de direção aproximadamente norte-sul, paralelos ao contato com a Formação Hilário (a oeste).

A análise de lineamentos em toda área mapeada resultou em 409 lineamentos (Fig. 
2A), com um máximo robusto entre NE-SW e ENE-WSW, de direção média $N 60^{\circ} E$, e um segundo máximo observado com direção NWSE em diagrama tipo roseta de frequência (Fig. 2C). Esses resultados são coerentes com as descrições estruturais de Gastal et al. (2015) e Lopes et al. (2018). De forma contrastante, 91 lineamentos traçados sobre as estruturas circulares apresentam uma distribuição que tende a ser concêntrica nas margens e internamente radial, estruturando a sua expressão no relevo, respectivamente delimitada por cristas semi-circulares e apresentando redes de drenagem radial-centrípetas. Essas drenagens convergem para cursos d'água axiais, condicionados por lineamentos NNW-SSE, que em ambas as estruturas circulares fluem para NNW, paralelas ao maior alongamento de cada uma destas (Fig. 2B). O resultado apresentado em diagrama de roseta (Fig. 2D) indica um máximo de direções em torno de E-W, com maior concentração WNW-ESSE. Máximos secundários de intensidade semelhante entre si ocorrem dispersos em NW-SE, NNE-SSW e ENEWSW, desta forma confirmando o caráter circular das estruturas observadas.

\subsection{Petrografia do andesito da Formação Hilário}

As estruturas circulares estudadas estão encaixadas em andesito (Fig. 3A), que é predominante em relação aos seus equivalentes piroclásticos aflorantes na região (Fig. 2A deste trabalho e Fig. 5 de Lopes et al., 2018). Este mesmo andesito é observado de forma característica como piroclastos dentro das estruturas circulares (Fig. 3B). O andesito é porfirítico, apresentando fenocristais de plagioclásio da ordem de 0,5 a 2 $\mathrm{mm}$, mas que podem chegar a até $8 \mathrm{~mm}$, imersos em matriz muito fina a afanítica (microcristalina). Fenocristais milimétricos de clinopiroxênio, por vezes arredondados, também são comuns. Amígdalas normalmente ocorrem de forma esparsa, e estão preenchidas por calcita, quartzo, opacos e/ou clorita. Tanto fenocristais quanto minerais da matriz e amigdalas apresentamse frequentemente orientados, caracterizando textura traquítica/traquitoide, dada pelo fluxo do derrame (Fig. 3B).

\subsection{Diatremas e brechas piroclásticas - aspectos de campo}

No interior das estruturas circulares ocorre uma brecha piroclástica constituída por fragmentos de andesito com tamanhos lápili e blocos, geralmente de dezenas de centímetros (Fig. 4A e B), mas localmente chegando até cerca de $1 \mathrm{~m}$ (Fig. 5A e B - ponto SL-2062). Estes fragmentos estão imersos em uma matriz de cinza vulcânica composta predominantemente por cristaloclastos de plagioclásio e litoclastos de andesito milimétricos a sub-milimétricos ( \pm vidro?), de aspecto granular, com uma porosidade parcialmente preenchida por calcita (Fig. 4C). Os piroclastos observados na brecha têm formas diversas, variando de angulosos a arredondados, por vezes com bordas reentrantes. É comum observar fragmentos maiores fraturados, partidos por fraturas transgranulares propagadas através da matriz, assim como fragmentos vizinhos preservados nas formas que sugerem o seu encaixe (Fig. 4D). Estas fraturas são frequentemente preenchidas por calcita. $\mathrm{O}$ andesito encaixante dos diatremas é basicamente a única rocha observada como fragmentos (piroclastos) dentro da brecha. Há uma aparente maior diversidade de tipos de andesitos (em termos de cores e texturas) dentre os fragmentos tamanho cinza e lápili menor que $1 \mathrm{~cm}$, enquanto os maiores fragmentos se assemelham entre si. Uma possível causa para a diferença observada nas cores dos clastos menores é a alteração hidrotermal diferencial, aparentemente mais intensa nos fragmentos menores, que também são mais arredondados (Fig. 4D).

A ocorrência desta brecha piroclástica circunscrita às estruturas circulares permite interpretar estas estruturas como diatremas ou cones vulcânicos. Entre a borda (SL-2012) e o centro do diatrema leste (SL-2062) há um expressivo aumento no tamanho dos blocos observados, sendo que blocos de até $50 \mathrm{~cm}$ são abundantes no centro, podendo chegar até ca. $1 \mathrm{~m}$ de comprimento máximo (Fig. 5A e B). Neste caso, há uma tendência dos blocos maiores preservarem ao menos algumas faces retas, apesar de exibirem abundantes formas 

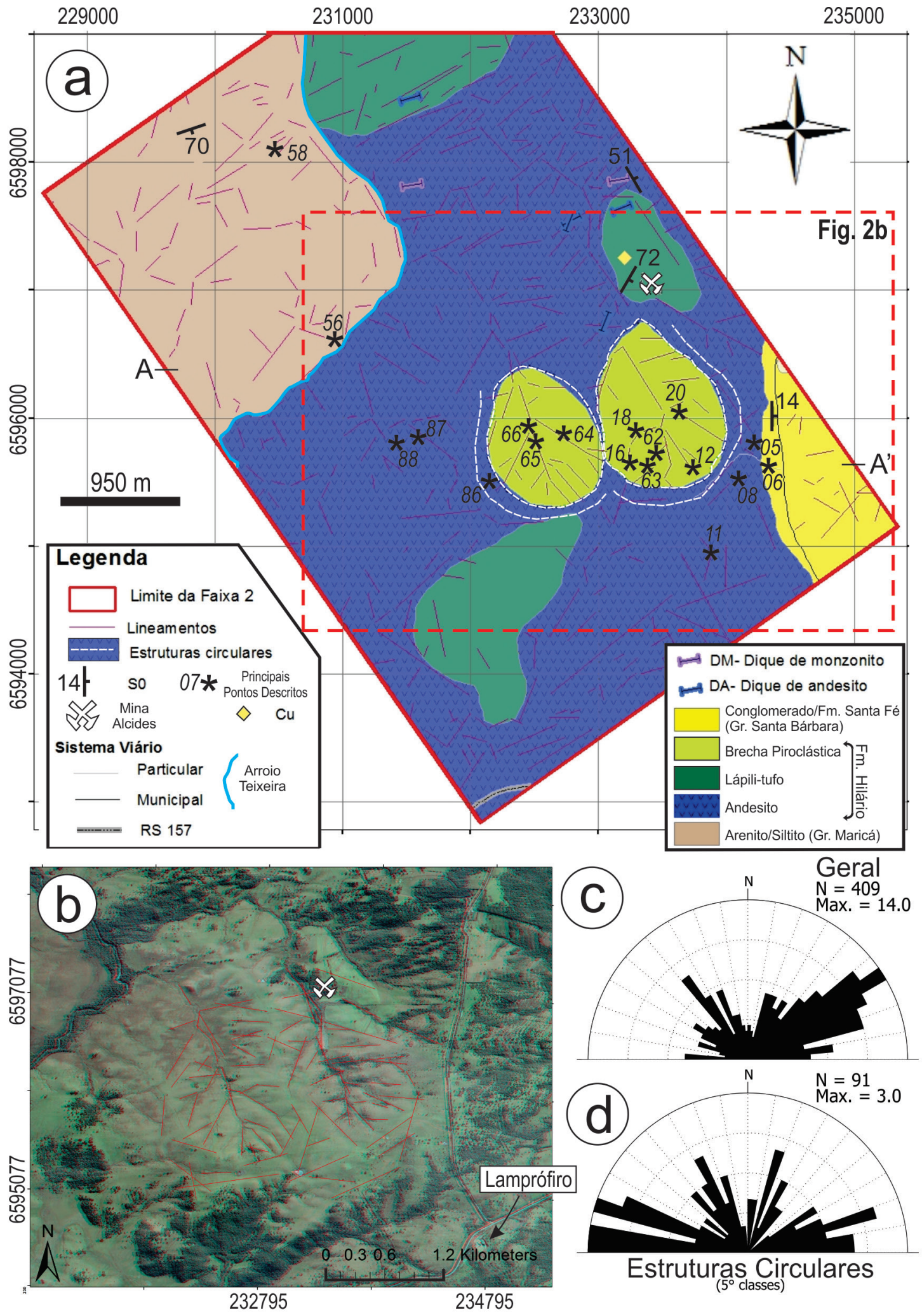

Estruturas Circulares

Figura 2. Resultados do mapeamento geológico da área de estudo. A) Mapa geológico da área de estudo com indicação da área da figura 2B; os principais pontos descritos são indicados com sua nomenclatura simplificada (e.g. ponto SL2012 = 12); B) Anaglifo das estruturas circulares estudadas (imagens do Google Earth ${ }^{\mathrm{TM}}$ ), com lineamentos circunscritos traçados em vermelho; C) Diagrama de roseta de lineamentos traçado na área de mapeamento; D) Diagrama de roseta de lineamentos circunscritos às estruturas circulares.

Figure 2. Geological mapping of the study area. A) Geological map of study area, indicating area of figure 2B; the main described outcrops are indicated with simplified nomenclature (e.g. outcrop SL-2012 = 12); B) Circular structures anaglyph (made with Google Earth ${ }^{T M}$ imagery), with lineaments in red; $C$ ) Rose diagram of lineaments traced in the mapping area and D) Rose diagram of lineaments circumscribed to the circular structures. 

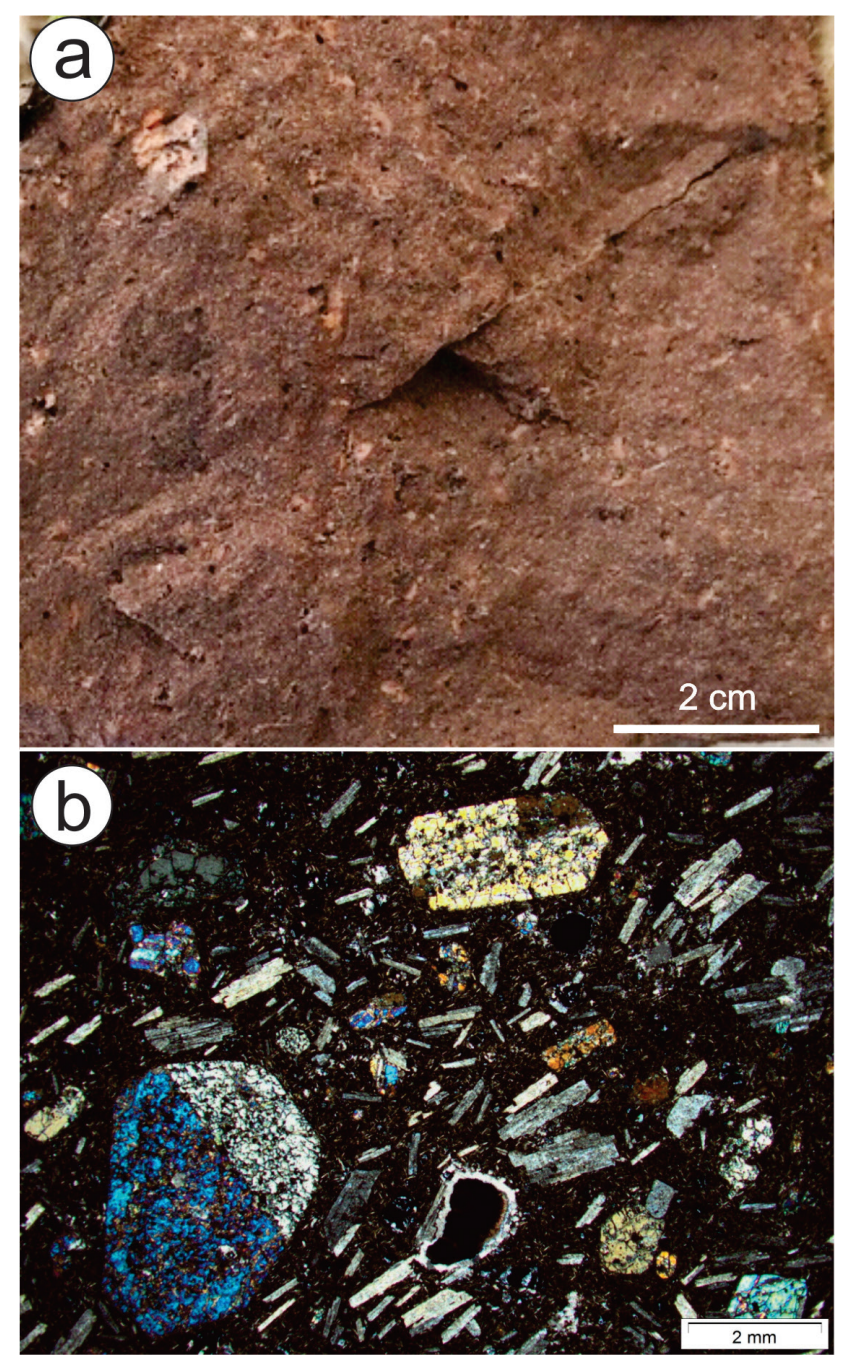

Figura 3. Aspectos de campo e petrográficos do andesito da Formação Hilário nas Minas do Seival. A) Amostra representativa do andesito, com esparsos fenocristais de até $5 \mathrm{~mm}$ de plagioclásio em matriz muito fina (ponto SL-2005); B) Aspecto típico do andesito observado em um piroclasto da estrutura circular leste (ponto SL-2012, amostra SL-2012A).

Figure 3. Field and petrographic aspects of the Hilario $\mathrm{Fm}$. andesites. A) Andesite representative sample, with up to $5 \mathrm{~mm}$ sparse plagioclase phenocrysts in a very finegrained matrix (SL-2005); B) Typical aspect of the andesite observed in one pyroclast from eastern circular structure (SL-2012 outcrop; sample SL-2012A).

reentrantes e sinuosas, sendo raramente arredondados, enquanto os blocos menores tendem a ser mais arredondados.

Fraturas são observadas em abundância, sendo aparentemente responsáveis pela fragmentação in situ dos blocos que compõem a brecha piroclástica (Fig. 4D e 5C). O preenchimento destas fraturas por carbonato branco (possivelmente calcita) localmente forma bolsões centimétricos condicionados pela intersecção de fraturas (Fig. 5D - SL-2063).
A geomorfologia da estrutura circular do diatrema oeste é observada nitidamente em campo a partir de uma vista para o oeste (entre os pontos SL-2063 e SL-2064), como uma crista semi-circular, em forma de ferradura, com a concavidade voltada para o norte (Fig. 6A). Também é possível observar a rede de drenagens radial centrípeta, convergente no centro do diatrema em uma drenagem axial com fluxo para o norte/NNW.

A rocha aflorante no diatrema oeste é basicamente a mesma brecha piroclástica observada no diatrema leste, com fragmentos da mesma natureza e ordem de tamanho (Fig. 6B). Medidas estruturais obtidas no diatrema oeste mostram por um lado um máximo de direção NNE a NE, coerente com o trend deformacional principal descrito para a área (Lopes et al., 2018) e também observado nos lineamentos da área mapeada (Fig. 2C). Por outro lado, apesar do pequeno número de medidas, também é observável uma distribuição de estruturas em quase todos os quadrantes, o que confirma o caráter circular da estrutura do diatrema, como também ilustrado por seu padrão de lineamentos (Fig. 2D). Este padrão também é semelhante ao das estruturas reportadas para a Mina Alcides (Lopes et al., 2018), distante menos de 500 m do diatrema leste, para o norte (Fig. 2B).

\subsection{Petrografia das brechas piroclásticas}

A rocha típica dos diatremas é uma brecha piroclástica (Fig. 4, 5 e 6B). Quando observada distante dos maiores blocos, a rocha se assemelha a um lápili-tufo (amostra SL2012E), sendo representante da matriz da brecha piroclástica (Fig. 7A). Fragmentos de andesito tamanho lápili são abundantes, de formas arredondadas a angulosas (Fig. 7B). A textura porfirítica é comum a todos estes fragmentos, caracterizada por fenocristais subédricos de plagioclásio de 1 a $2 \mathrm{~mm}$ de comprimento, apresentando orientação preferencial, porém o aspecto da matriz é variável em distintos piroclastos. Alguns fragmentos de andesito também apresentam fenocristais milimétricos de clinopiroxênio. A maior parte dos lápili de andesito apresentam matriz microcristalina, geralmente 


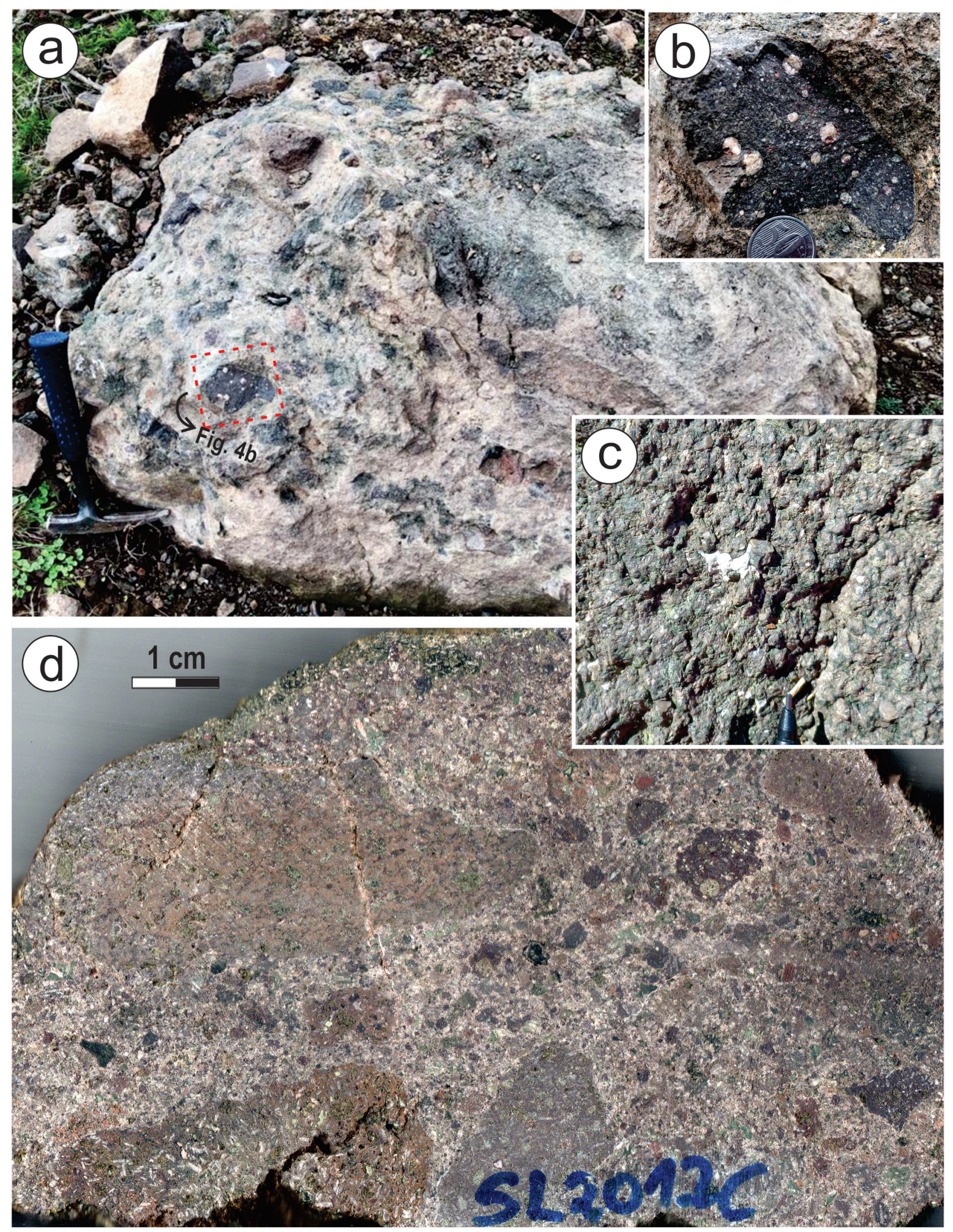

Figura 4. Aspectos de campo e petrográficos da brecha piroclástica no diatrema leste (ponto SL-2012). A) Aspecto de campo da brecha piroclástica, com indicação da área expandida na figura 4B; B) Detalhe de clasto de andesito; C) Detalhe da matriz da brecha piroclástica, com "cimentação" de calcita ao centro; D) Amostra (SL-2012C) de brecha piroclástica onde todos os fragmentos são de andesito porfirítico. Fraturas discretas transgranulares são preenchidas por calcita. Figure 4. Field and petrgraphic aspects of the eastern diatreme pyroclastic breccia (SL-2012 outcrop). A) Pyroclastic breccia field aspect, indicating area expanded in figure 4B; B) Andesite clast detail; C) Pyroclastic breccia matrix detail, with calcite "cement" in the center; D) Pyroclastic breccia sample (SL-2012C) where all fragments are from porphyritic andesite. Discrete, transgranular fractures are filled by calcite. 

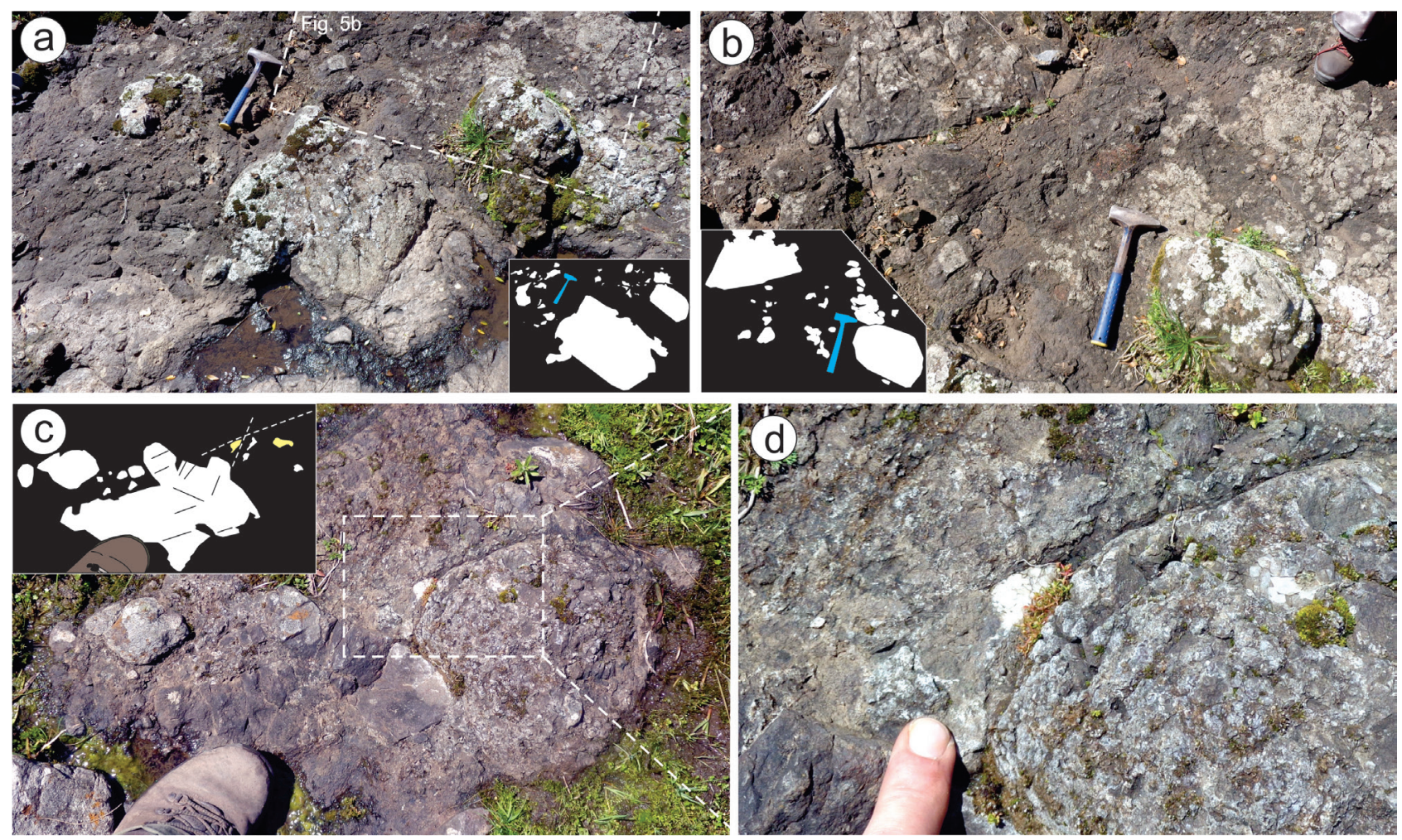

Figura 5. Aspectos de campo da brecha piroclástica no diatrema leste, onde os insets apresentam croquis esquemáticos (em branco, os maiores piroclastos; em preto, a matriz). A) Brecha piroclástica com blocos de andesito de até $1 \mathrm{~m}$, apresentando formas variadas. 0 retângulo indica a área da figura 5B (ponto SL-2062); B) Detalhe onde se observa blocos de andesito com até ca. $40 \mathrm{~cm}$, angulosos e arredondados; C) Brecha piroclástica com blocos arredondados a angulosos de andesito, de até $25 \mathrm{~cm}$; D) No detalhe, calcita preenche porosidade da matriz e forma um bolsão na intersecção de um par de fraturas (ponto SL-2063).

Figure 5. Field aspects of the pyroclastic breccia at the eastern diatreme. Sketches are presented in figure insets (major pyroclasts in white; matrix in black). A) Pyroclastic breccia with up to $1 \mathrm{~m}$ andesite blocks with diverse shapes. The dashed rectangle indicate area of figure 5B (SL-2062 outcrop); B) Detail of angular to rounded andesite blocks with up to $40 \mathrm{~cm} ;$ C) Pyroclastic breccia with rounded to angular andesite blocks with up to $25 \mathrm{~cm}$; D) In detail, calcite is observed filling matrix pores and the intersection between two fractures (SL-2063 outcrop).

com intensa alteração (tons amarelo-escuro e esverdeados na Fig. 7B). Mais raramente a matriz destes fragmentos andesíticos tem aspecto opaco, podendo ser produto de intensa alteração hidrotermal ou uma característica primária (matriz vítrea).

Especificamente em uma amostra descrita (SL-2012E) foi observado um fragmento tamanho lápili (4 cm de dimensão máxima) de uma rocha vulcânica esverdeada distinta, onde se observa elevada proporção de amígdalas, diferente do andesito tipicamente descrito, assemelhando-se a uma escória vulcânica (Fig. 7C). As amígdalas são preenchidas por material preto, fosco e afanítico, com fraturas de aspecto conchoidal, sendo interpretado como antigo vidro vulcânico.
A matriz desta rocha piroclástica é constituída por cinza vulcânica (tamanho de grão $\leq 2 \mathrm{~mm}$ ). Esta cinza é composta por abundantes cristaloclastos de plagioclásio, de tamanho igual ou inferior aos fenocristais observados nos lápili de andesito, e muito semelhantes a estes, porém de formas angulosas, raros cristaloclastos de clinopiroxênio, litoclastos de formas variadas, além de material de grão muito fino (Fig. 7D e 7E).

Quando observada nas proximidades de grandes blocos, é comum encontrar piroclastos de andesito tamanho bloco e lápili intensamente fraturados (Fig. 8A). Muitas destas fraturas são transgranulares, atravessando os fragmentos de andesito e cortando a matriz. Estas fraturas são frequentemente preenchidas 

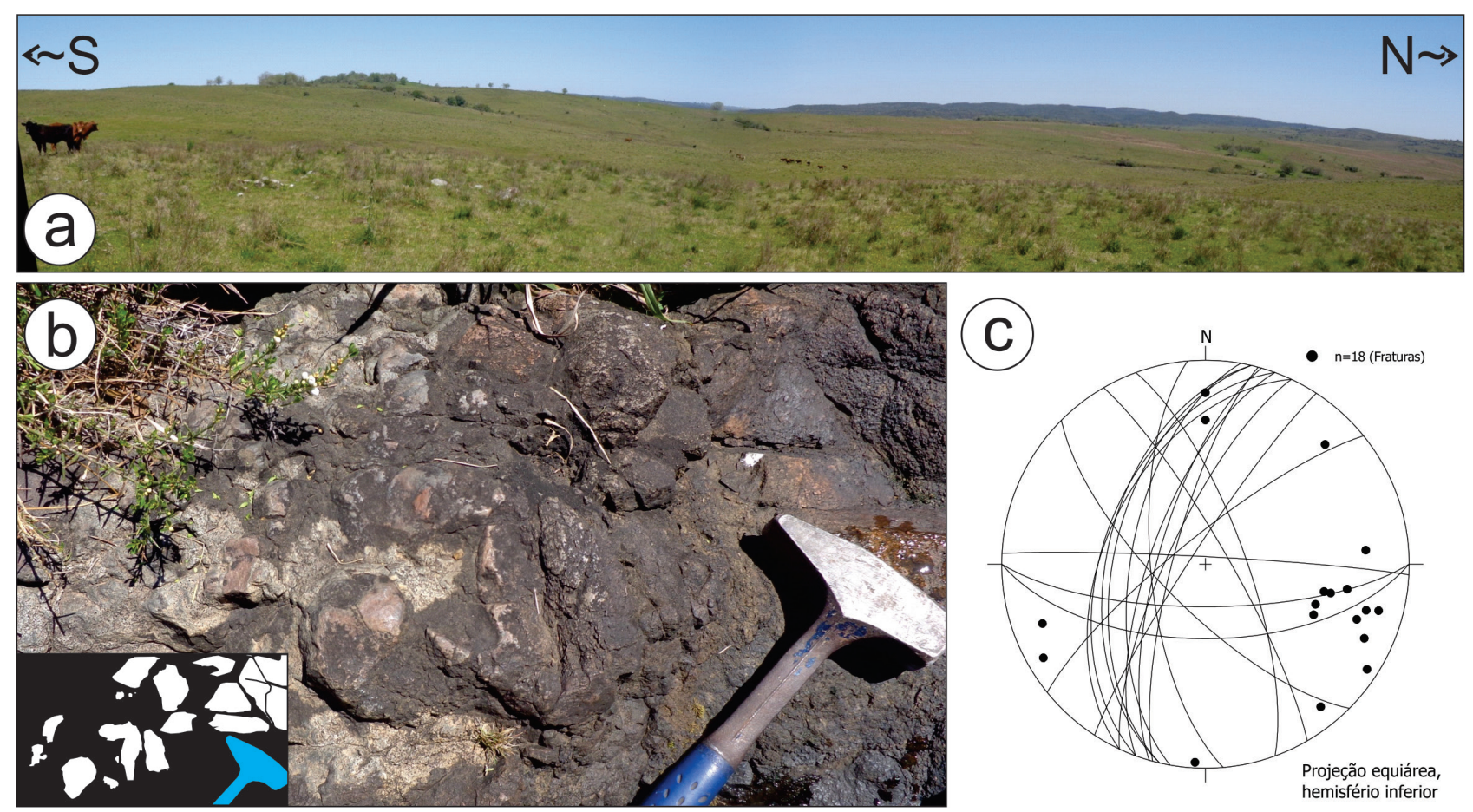

Figura 6. Aspectos geológicos do diatrema oeste. A) Típica paisagem do diatrema oeste em fotomosaico panorâmico com vista para oeste; B) Aspecto de campo da brecha piroclástica (SL-2066); C) Diagrama equiárea de pólos e planos de fraturas medidos no diatrema oeste (hemisfério inferior; $\mathrm{n}=18$ ).

Figure 6. Western diatreme geological aspects. A) Typical landscape of the western diatreme observed in a panoramic photomosaic looking to west; B) Field aspect of pyroclastic breccia (SL-2066); C) Equal area stereonet of fractures (and poles) from the western diatreme (lower hemisphere; $n=18$ ).

por calcita. O contraste textural entre os fragmentos de andesito e a matriz de grão fino é aparentemente acentuado por alteração hidrotermal, responsável pelo avermelhamento (oxidação) e esbranquecimento (lixiviação) da matriz dos clastos de andesito (Fig. 8A e B), em contraste com a matriz da brecha, escurecida por cominuição e localmente esverdeada (cloritizada ou localmente epidotizada). Esta feição de alteração hidrotermal da matriz restrita à margem dos blocos de andesito brechado é semelhante à feição observada por Lopes et al. (2014) em amostra de furos de sondagem da região que intercepta o contato entre um dique de andesito e brechas piroclásticas (ver figura 6B de Lopes et al., 2014).

O contato entre bloco e matriz da brecha observado ao microscópio ilustra a combinação de processos de fragmentação e transformação mineral (Fig. 8B e C). O contato é marcado pelo desenvolvimento heterogêneo de uma margem alterada de espessura milimétrica, com a coloração avermelhada dos blocos passando para um rosa pálido esbranquiçado, pobre em óxidos (i.e. lixiviada). Os minerais opacos são aparentemente concentrados na matriz da brecha. Fraturas intergranulares, cortando mais de um fragmento, assim como a matriz, podem ser observadas (Fig. 8B e C). A forma localmente curvilínea das fraturas, o fraturamento dos clastos in situ, e o preenchimento por calcita, observável tanto em macro (Fig. 8A) quanto em micro-escala (Fig. 8B e C), sugerem a participação de fluidos durante o fraturamento.

\subsection{Levantamento Gamaespectrométrico}

Medidas gamaespectrométricas foram tomadas em pontos representativos do andesito e da brecha piroclástica, respectivamente fora e dentro do diatrema leste, e também em um afloramento do conglomerado da Formação Santa Fé (Grupo Santa Bárbara), ao longo de uma seção geológica. Os resultados gamaespectrométricos são apresentados na tabela 1, assim como ilustrados na figura 9, e também são comparados com os dados geoquímicos de rochas piroclásticas e efusivas da Formação Hilário da região das Minas do Seival apresentados por Lopes et al. (2014). 

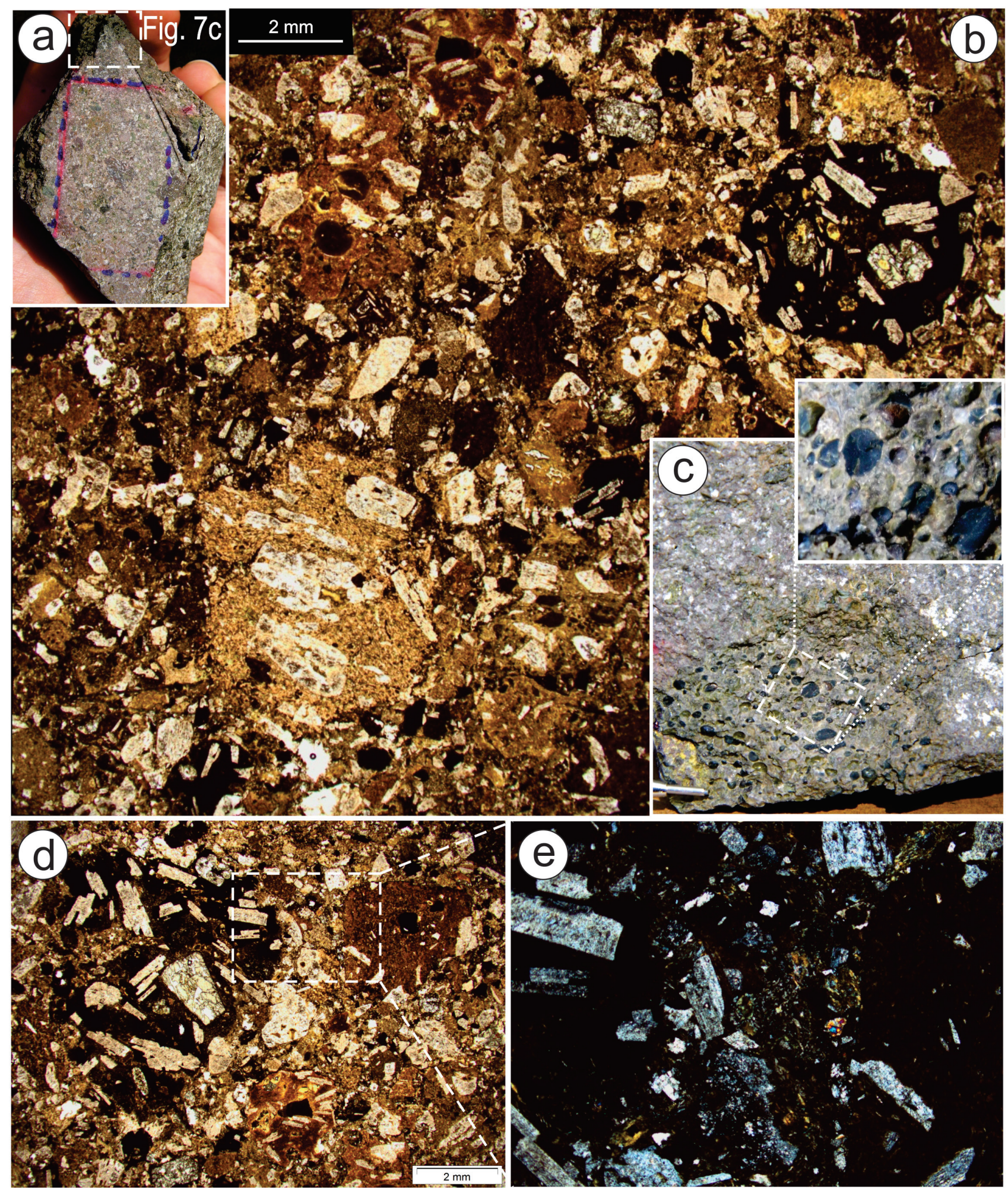

Figura 7. Aspectos petrográficos da matriz da brecha piroclástica. A) Amostra de mão (SL-2012E); B) Aspecto geral da matriz da brecha piroclástica (nicóis paralelos); C) Detalhe de escória vulcânica tamanho lápili em amostra de mão (escala: ponta da lapiseira $=5 \mathrm{~mm}$ ); D) Contraste textural entre fragmento lápili de andesito e matriz da brecha piroclástica (nicóis paralelos); E) Detalhe da textura da matriz (nicóis cruzados - a base da fotografia equivale a 3,5 mm de largura). Figure 7. Petrographic aspects of the pyroclastic breccia matrix. A) Hand sample (SL-2012E); B) General aspect of the pyroclastic breccia matrix (parallel polarizers); C) Detail of lapilli-sized volcanic scoria at hand sample (the pencil tip for scale is $5 \mathrm{~mm}$ long); D) Textural contrast between lapilli-sized andesite fragment and the pyroclastic breccia matrix (parallel polarizers); E) Detail of matrix texture (crossed polarizers - the photograph base is $3.5 \mathrm{~mm}$ wide). 


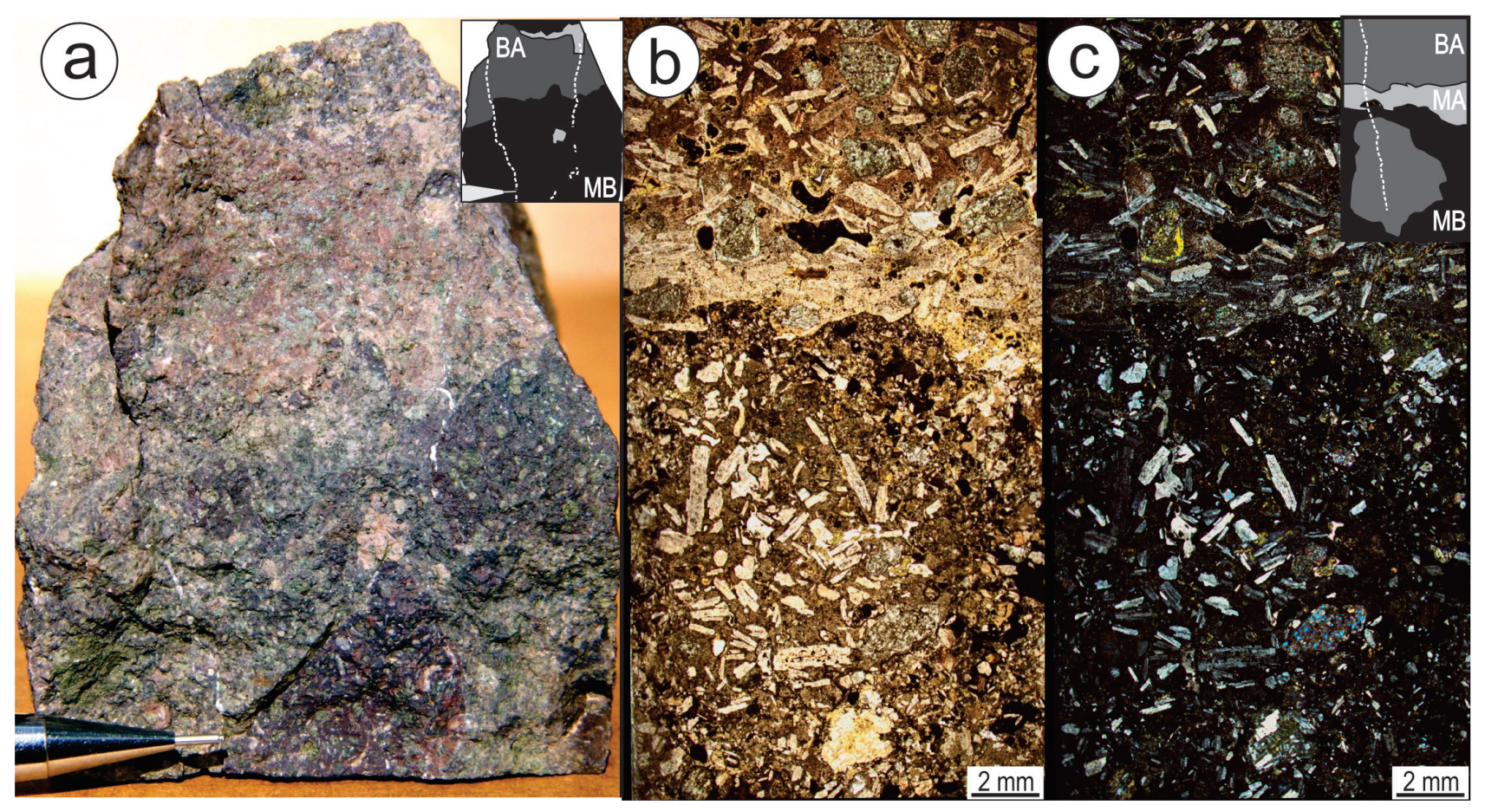

Figura 8. Aspectos petrográficos da brecha piroclástica (amostra SL-2012D). A) Bloco de andesito fraturado imerso na matriz da brecha; B) Mosaico de fotomicrografias da área de contato entre um bloco de andesito e a matriz da brecha em luz natural (plano-polarizada); C) Mosaico de fotomicrografias da mesma área, em luz polarizada (nicóis cruzados). Croquis esquemáticos são apresentados, sendo BA = bloco de andesito; $\mathrm{MA}$ = margem alterada; $\mathrm{MB}=$ matriz da brecha; e a linha branca tracejada indica fraturas preenchidas por carbonato.

Figure 8. Petrographic aspects of the pyroclastic breccia (sample SL-2012D). A) Fractured andesite block immerse in the breccia matrix; B) Photomicrographic mosaic of the contact between andesite block and breccia matrix at planepolarized; $C$ ) Photomicrographic mosaic of the same area, under crossed-polarized light. Sketches are presented, where $B A=$ andesite block; $M A=$ altered matrix; $M B$ = breccia matrix; and the traced white line indicate fractures filled by carbonate.

Tabela 1. Resultados de gamaespectrometria obtidos ao longo da seção geológica. A incerteza do valor médio corresponde às estimativas de desvio padrão para cada litologia. $a=$ andesito; $b=$ brecha piroclástica; $c=$ conglomerado.

Table 1. Gammaspectrometric results obtained along the geological section. The uncertainities in the average value corresponds to the standard deviation of each lithology. $a=$ andesite; $b=$ pyroclastic breccia; $c=$ conglomerate.

\begin{tabular}{crrrrrrr}
\hline Ponto & K (\%) & $\mathbf{U}(\mathbf{p p m})$ & Th (ppm) & Total (cps) & K/U & U/Th & K/Th \\
\hline SL-2005 (a) & 4,3 & 2,2 & 26,9 & 5334 & 1,95 & 0,08 & 0,16 \\
SL-2006 (c) & 3,3 & 2,2 & 17,3 & 3790 & 1,50 & 0,13 & 0,19 \\
SL-2007 (a) & 5 & 6,2 & 13,2 & 5074 & 0,81 & 0,47 & 0,38 \\
SL-2008 (a) & 3,8 & 4,9 & 17,5 & 4804 & 0,78 & 0,28 & 0,22 \\
SL-2010 (b) & 2 & 1,1 & 2,8 & 2398 & 1,82 & 0,39 & 0,71 \\
SL-2012 (b) & 1,3 & 4,5 & 3,3 & 2154 & 0,29 & 1,36 & 0,39 \\
SL-2014 (b) & 1,7 & 2,5 & 7 & 1949 & 0,68 & 0,36 & 0,24 \\
SL-2016 (b) & 1,3 & 3,3 & 8,3 & 2394 & 0,39 & 0,40 & 0,16 \\
SL-2018 (b) & 2 & 3,2 & 7,3 & 2337 & 0,63 & 0,44 & 0,27 \\
SL-2020 (b) & 1,9 & 3,2 & 8 & 2282 & 0,59 & 0,40 & 0,24 \\
Média (a) & $4,4 \pm 0,6$ & $4,4 \pm 2,0$ & $19,2 \pm 7,0$ & $5070 \pm 265$ & 0,98 & 0,23 & 0,22 \\
Média (b) & $1,7 \pm 0,3$ & $3 \pm 1,1$ & $6,1 \pm 2,4$ & $2252 \pm 173$ & 0,57 & 0,48 & 0,27 \\
\hline
\end{tabular}


O comportamento gamaespectrométrico da brecha piroclástica e do andesito da Formação Hilário é contrastante, e também se distingue satisfatoriamente do conglomerado analisado da Formação Santa Fé. A brecha possui menos da metade do conteúdo radioativo quando comparado ao andesito em termos de contagem total (cps - contagem por segundo). Enquanto a brecha apresenta entre 1949 e 2398 cps, com média de $2252 \pm 173$ cps, o andesito varia de 4804 e 5334 cps, com média de $5070 \pm 265$ cps, e o conglomerado da Formação Santa Fé apresenta um valor intermediário de 3790 cps (Fig. 9A e B).

A proporção elementar de potássio e tório também é diagnóstica, sendo o potássio entre 1,3 e $2 \%$ para a brecha, e entre 3,8 e $5 \%$ para o andesito (Fig. 9A), este último sendo diagnóstico do caráter shoshonítico destas rochas (e.g. Lima \& Nardi, 1998; Lopes et al., 2014). Novamente o conglomerado, com 3,3\%, apresenta valor intermediário. O tório da brecha fica entre 2,8 e 8,3 ppm, enquanto o andesito tem 13,2 a 26,9 ppm (Fig. 9C e D), chegando em outra ordem de grandeza e se assemelhando ao conglomerado (17,3 ppm). Os valores de urânio das amostras se sobrepõem no intervalo entre 1,1 e 6,2 ppm, sendo a grande maioria inferior a 5 ppm (Fig. 9B e D). O conjunto dos parâmetros medidos permite a distinção entre os grupos de rochas analisados (Fig. 9).

\section{Discussões}

\subsection{Correlação geoquímica}

Ao compararmos os dados gamaespectrométricos com a composição geoquímica das rochas da Formação Hilário da região das Minas do Seival (Lopes et al., 2014), nos gráficos $U$ vs. Th e $\mathrm{K}_{2} \mathrm{O}$ vs. Th (Fig. $9 \mathrm{C}$ e D), fica evidente o agrupamento composicional de todas as rochas em um único trend de correlação positiva. Isto confirma a origem comum e a classificação de todas as amostras vulcânicas como parte da Formação Hilário. As brechas piroclásticas tem similaridade com as amostras de lápili-tufo (de forma geral: Th $<10$ ppm; $U<3,5$ ppm; $\mathrm{K}_{2} \mathrm{O} \leq 2,5 \%$ ), interpretado como indicativo da natureza semelhante de ambas litologias. Os andesitos analisados apresentam boa correlação com as análises da literatura em ambos gráficos, e os altos valores de $\mathrm{K}_{2} \mathrm{O}$ confirmam o caráter shoshonítico característico da Formação Hilário (Nardi \& Lima, 1985, 1988; Lima \& Nardi, 1998; Lopes et al., 2014).

\subsection{Origem dos diatremas e das brechas piroclásticas}

O principal processo identificado para a formação das brechas piroclásticas foi a fragmentação in situ de andesitos da Formação Hilário, incorporados como blocos ( $\leq 1 \mathrm{~m})$, lápili e cinza vulcânica (cristaloclastos e litoclastos), e documentada por fraturas transgranulares e intergranulares. A maioria destas fraturas dividem blocos de andesito sem acumular deslocamento significativo, de forma que blocos adjacentes muitas vezes têm formas que sugerem seu encaixe (Fig. 4D, 5 e 6B). Muitas fraturas que cortam também a matriz da brecha piroclástica, às vezes apresentam forma curviplanar e são geralmente preenchidas por calcita, apontando o papel de fluidos no processo de brechação (Fig. $4 C, 4 D, 5 C, 6 B$ e 8 ).

A ausência de acamamento da brecha piroclástica que ocorre dentro dos diatremas sugere tratar-se de uma seção inferior da chaminé vulcânica (Jerram \& Petford, 2011; White \& Ross, 2011; Mundula et al., 2013), enquanto a natureza monomítica dos fragmentos permite classificála como uma brecha de contato, segundo os critérios de Lorenz \& Kurszlaukis (2006), ou ainda como uma brecha de subsidência, se considerarmos adicionalmente a abundância de fraturas, algumas destas potencialmente cisalhantes (falhas).

A relação espacial dos diatremas com os lamprófiros espessartíticos que afloram a cerca de 1,5 km, à SSE (Lima et al., 2007b - vide Fig. 2B) é um elemento que fortalece a interpretação das estruturas circulares enquanto diatremas, sugerida aqui a partir das evidências já descritas. A posição da Mina Alcides, localizada na intersecção de um lineamento NW-SE com o lineamento axial do diatrema leste, de direção NNW-SSE, a cerca de $500 \mathrm{~m}$ a norte desta estrutura circular, é um elemento adicional a ser 

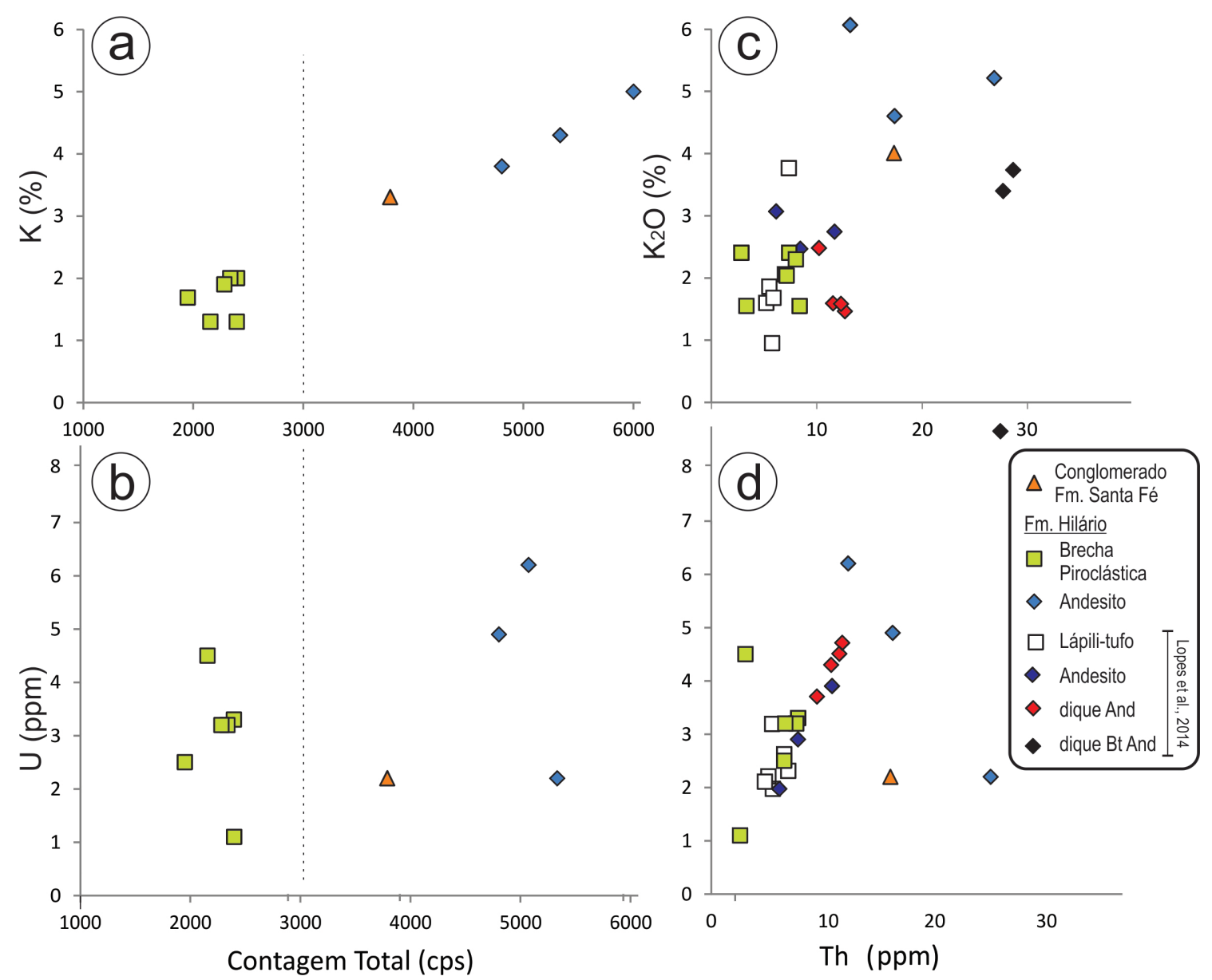

Figura 9. Gamaespectrometria de andesitos e brechas piroclásticas da Formação Hilário (Grupo Bom Jardim) e de um conglomerado da Formação Santa Fé (Grupo Santa Bárbara) da região de Minas do Seival comparados com dados geoquímicos de rocha total da Formação Hilário apresentados por Lopes et al. (2014). A) Contagem total (cps) vs. K (\%); B) Contagem total (cps) vs. U (ppm); C) Th (ppm) vs. K2O (\%); D) Th (ppm) vs. U (ppm).

Figure 9. Gammaspectrometry of andesite and pyroclastic breccia of Hilário Formation (Bom Jardim Group), as well as from one conglomerate of Santa Fé Formation (Santa Bárbara Group) from Seival Mine region compared with Hilário Formation geochemical data presented by Lopes et al. (2014). A) Total count (cps) vs. K (\%); B) Total count (cps) vs. U (ppm); C) Th (ppm) vs. K2O (\%); D) Th (ppm) vs. U (ppm).

levado em consideração na evolução conjunta do sistema pluto-vulcânico e mineralizador da Associação Shoshonítica de Lavras do Sul. Em verdade, estes três elementos (Mina Alcides - diatrema leste - lamprófiro espessartítico) estão alinhados ao longo da continuidade do lineamento axial do diatrema leste, em uma distância de cerca de 3 km (vide Fig. 2C). Futuros trabalhos devem testar essa correlação espacial e temporal de forma mais específica, incluindo a análise estrutural e a comparação de evidências de hidrotermalismo e mineralizações associadas aos três locais, visto que a mineralização na área é comumente atribuída a intrusões tardias no sistema (e.g. Fontana et al., 2019), e em especial, a magmas lamprofíricos (e.g. Gastal et al., 2015).

\subsection{Seção geológica integrada}

Uma seção geológica cruzando os diatremas reconhecidos nas Minas do Seival é proposta a partir da integração dos dados apresentados (Fig.10A - vide Fig. 2A para localização e legenda). De leste para oeste, a área mapeada tem afloramentos de conglomerados da Formação Santa Fé (Grupo Santa Bárbara) com baixo ângulo de mergulho para leste $\left(\sim 14^{\circ}\right)$. Estes conglomerados repousam sobre as rochas da Formação Hilário, cujo contato é dado por uma discordância angular.

A Formação Hilário tem predominância de andesitos sobre rochas piroclásticas, e na área de estudo está basculada com médio (a alto?) ângulo 
de mergulho para nordeste e sudeste. Rochas piroclásticas ocorrem abaixo e possivelmente também acima dos andesitos circundantes, do ponto de vista estratigráfico, aflorando tanto a norte dos diatremas, próximo da Mina Alcides, quanto a sul (Fig. 2A e B). Ressalta-se, por um lado, o baixo número de medidas de acamamento obtidas durante o mapeamento realizado. Por outro lado, é notável que atitudes variáveis de acamamento são reportadas na bibliografia, com mergulhos para sudoeste (Toniolo et al., 2007; Gastal et al., 2015) ou noroeste (Lopes et al., 2018, 2019). Futuros estudos nesta área devem concentrar esforços na obtenção de medidas confiáveis de acamamento vulcânico, com distribuição representativa.

Como principal resultado do presente trabalho, tem-se o reconhecimento de que a sequência vulcânica acamada da Formação Hilário é truncada por dois diatremas geminados, cada um com cerca de 1 km de diâmetro médio, dispostos lado-a-lado na direção E-W (Fig. 2 e 10A). A disposição dos diatremas geminados é muito semelhante ao ilustrado pelo modelo 3D esquemático de maar-diatrema proposto por Lorenz \& Kurszlaukis (2006), assim como pelos exemplos de maars em cadeias reconhecidos em distintas partes do globo por Graettinger (2018). Um perfil gamaespectrométrico B - B' ao longo do diatrema leste confirma o contraste litológico abrupto entre as brechas piroclásticas dos diatremas e os andesitos circundantes (Fig. 10B).

A porção oeste da área mapeada apresenta rochas sedimentares do Grupo Maricá, sendo separada da Formação Hilário por lineamentos que condicionam o Arroio Teixeira, interpretado como um contato tectônico. Observações de campo naquela região revelaram um forte basculamento de camadas com um alto ângulo de mergulho para sul ( 70 Fig. 10C).
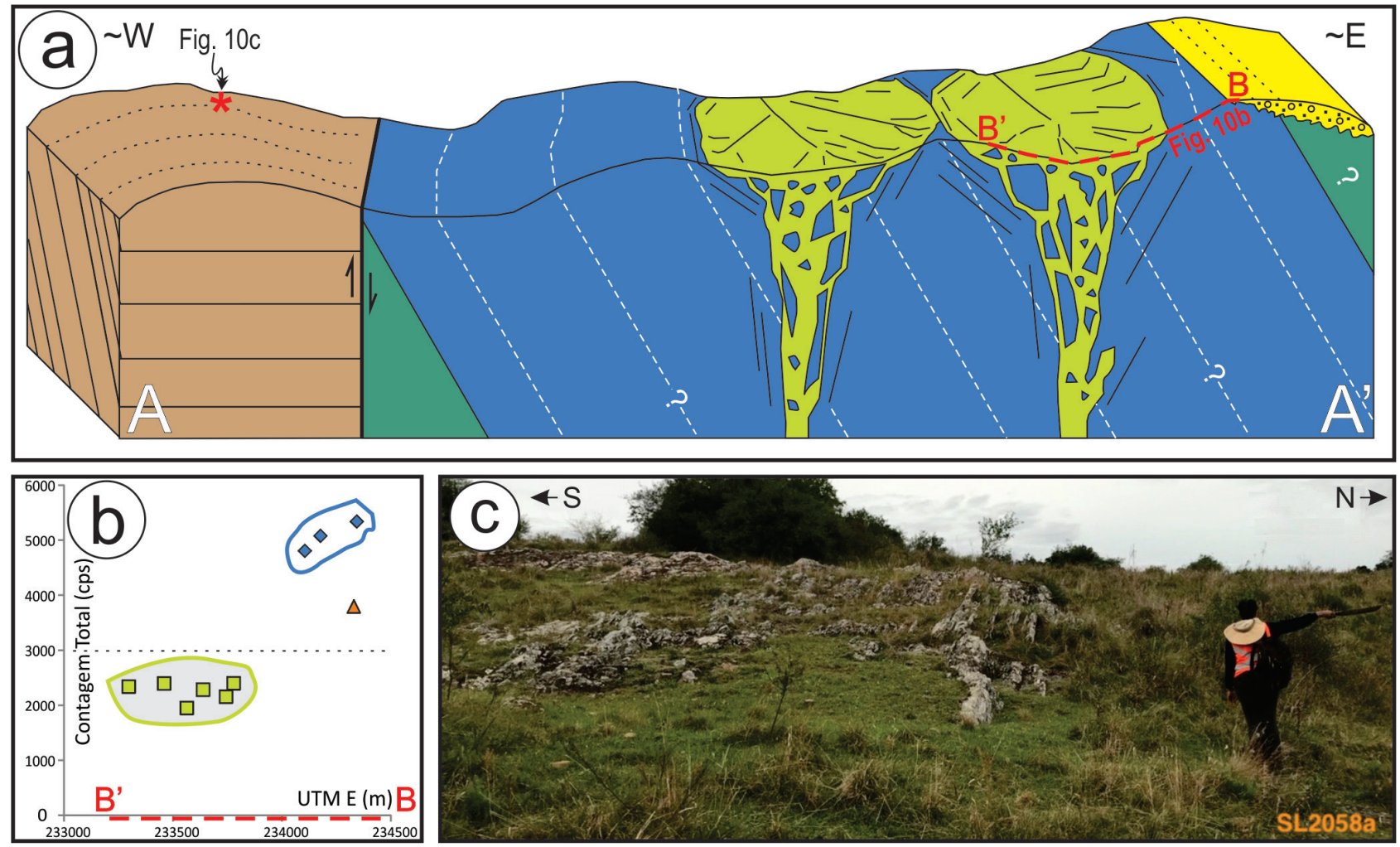

Figura 10. Seção geológica integrada. A) Seção geológica A - A' em bloco diagrama esquemático através dos diatremas das Minas do Seival, ilustrando os principais elementos estruturais da geologia local. A legenda é a mesma da figura $2 \mathrm{~A}$. B) Perfil gamaespectrométrico B - B' de contagem total através do diatrema leste. A legenda é a mesma da figura 9. C) Aspecto de campo de estratificação basculada em rochas sedimentares do Grupo Maricá, com alto ângulo de mergulho para sul.

Figure 10. Integrated geological cross-section. A) Block diagram section A - A' through the Seival Mine diatremes, showing main structural elements of the local geology. Legend is the same of figure $2 A$. B) Gammaspectrometric profile $B-B^{\prime}$ of total counts through the eastern diatreme. Legend is the same of figure 9. C) Field aspect of tilted stratification of sedimentary rocks of Maricá Group, steeply dipping towards the south. 


\section{Considerações finais}

Dois diatremas geminados são descritos como relictos de chaminés vulcânicas cortando a sequência acamada da Formação Hilário na porção sul da região de Minas do Seival, na Bacia do Camaquã. Os diatremas são reconhecidos como estruturas circulares e têm aproximadamente $1 \mathrm{~km}$ de diâmetro médio cada um, ocorrendo lado-a-lado na direção leste-oeste. As rochas aflorantes nestes diatremas são descritas como brechas piroclásticas monomíticas (brechas de contato ou de subsidência, segundo critérios de Lorenz \& Kurszlaukis, 2006).

A caracterização gamaespectrométrica de brechas piroclásticas e dos andesitos circundantes confirma o trabalho de mapeamento geológico. A comparação destes dados com a geoquímica de rocha total das rochas vulcânicas da Formação Hilário das Minas do Seival corrobora a correlação proposta, incluindo as brechas piroclásticas nesta unidade.

Evidências como fraturas intergranulares e transgranulares sugerem a fragmentação in situ do andesito encaixante como principal mecanismo de formação destas rochas. Fraturas curviplanares cortando a matriz, e o preenchimento de fraturas e da porosidade da brecha por calcita, sugerem que a fragmentação se deu na presença de fluidos, possivelmente concomitante a um dos eventos de alteração hidrotermal que afetou as rochas vulcânicas circundantes.

Essa ocorrência confirma a existência dos "antigos cones vulcânicos" mencionados por Ribeiro \& Fantinel (1978) para a área. As chaminés vulcânicas descritas constituem a primeira documentação material de um centro vulcânico na Formação Hilário (Grupo Bom Jardim da Bacia do Camaquã), e se agregam ao patrimônio geológico e à reconhecida geodiversidade de Caçapava do Sul (RS). Ainda, o presente trabalho ilustra o caráter indissociável entre ensino e investigação científica nas atividades didáticas de mapeamento geológico.

A presença dos diatremas descritos complementa o cenário de um campo vulcânico com interação freato-magmática para a
Formação Hilário a leste do Complexo Intrusivo Lavras do Sul, em um sistema plutono-vulcânico integrado em ambiente de colapso de caldeira. Trabalhos futuros devem investigar e testar a correlação da gênese dos diatremas com os eventos de hidrotermalismo e mineralização das Minas do Seival, assim como com os pulsos magmáticos pristinos tardios (i.e. diques traquiandesíticos e intrusões de lamprófiros) da Associação Shoshonítica Lavras do Sul.

Agradecimentos. AM, ET, LS e NFA agradecem à Sociedade Nacional de Combustíveis de Angola (SONANGOL) pelas bolsas de estudos e apoio financeiro durante a graduação. FMWT agradece ao CNPq pelo apoio financeiro (Proc. No 311204/2017-1). GBDT, RWL e FMWT agradecem ao pessoal do LASERCA (Graciela, Gustavo, Milena e Gabriel) pelo apoio logístico, ao Laboratório de Preparação de Amostras (Lauro e Adriano) pela confecção das lâminas petrográficas e a todos os 38 participantes das duas turmas de Exploração e Avaliação de Depósitos Minerais I e II ("Projeto 3") no ano de 2019. Os autores agradecem ao geólogo Marcelo Tatsch Lindenberg (Nexa Resources, PPGGEO-UFRGS) pelas instigantes discussões ocorridas em Lavras do Sul, assim como à crítica construtiva e revisões de Ronaldo Pierosan, de um revisor anônimo e do editor Edinei Koester.

\section{Referências}

Abre, P., Blanco, G., Gaucher, C., Frei, D. \& Frei, R. 2020. Provenance of the Late Ediacaran Rocha Formation, Cuchilla Dionisio Terrane, Uruguay: Tectonic implications on the assembly of Gondwana. Precambrian Research, 342: 105704.

Acocella, V. 2007. Understanding caldera structure and development: An overview of analogue models compared to natural calderas. EarthScience Reviews, 85: 126-160.

Almeida, R.P., Janikian, L., Fragoso-Cesar, A.R.S. \& Fambrini, G.L. 2010. The Ediacaran to Cambrian rift system of southeastern South America: tectonic implications. The Journal of Geology, 118(2): 145-161.

Almeida, R.P., Santos, M.G.M., Fragoso-Cesar, 
A.R.S., Janikian, L. \& Fambrini, G.L. 2012 Recurring extensional and strike-slip tectonics after the Neoproterozoic collisional events in the Southern Mantiqueira Province. Anais da Academia Brasileira de Ciências, 84(2): 347376.

Bitencourt, M.F. \& Nardi, L.V.S. 2000. Tectonic setting and sources of magmatism related to the Southern Brazilian Shear Belt. Revista Brasileira de Geociências, 30: 186-189.

Bongiolo, E.M., Renac, C., Mexias, A.S., Gomes, M.E.B., Ronchi, L.H. \& Patier-Mas, P. 2011. Evidence of Ediacaran glaciation in southernmost Brazil through magmatic to meteoric fluid circulation in the porphyryepithermal Au-Cu deposits of Lavras do Sul. Precambrian Research, 189: 404-419.

Borba, A.W., Maraschin, A.J., Lima Noronha, F., Casagrande, J. \& Mizusaki, A.M.P. 2007. Provenance of the sedimentar rocks of the Bom Jardim Group (Neoproterozoic, Southern Brazil): evidence from petrography, geochemistry and neodymium isotopes. Latin American Journal of Sedimentology and Basin Analysis, 14(1): 25-42.

Borba, A.W., Mizusaki, A.M.P., Santos, J.O.S., McNaughton, N.J., Onoe, A.T. \& Hartmann, L.A. 2008. U-Pb zircon and 40Ar-39Ar K-feldspar dating of syn-sedimentary volcanismof the Neoproterozoic Maricá Formation: constraining the age of foreland basin inception and inversion in the Camaquã Basin of southern Brazil. Basin Research, 20: 359375 .

Cole, J.W., Milner, D.M. \& Spinks, K.D. 2005. Calderas and caldera structures: a review. Earth-Science Reviews, 69: 1-26.

De Toni, G.B., Bitencourt, M.F., Nardi, L.V.S., Florisbal, L.M., Almeida, B.S. \& Geraldes, M. 2020. Dom Feliciano Belt orogenic cycle tracked by its pre-collisional magmatism: the Tonian (ca. $800 \mathrm{Ma}$ ) Porto Belo Complex and its correlations in southern Brazil and Uruguay. Precambrian Research, 342: 105702.

Fontana, E., Mexias, A.S., Renac, C., Nardi, L.V.S., Lopes, R.W., Barats, A. \& Gomes, M.E.B. 2017. Hydrothermal alteration of volcanic rocks in Seival Mine Cu-mineralization - Camaquã Basin - Brazil (part 1): Chloritization process and geochemical dispersion in alteration halos. Journal of Geochemical Exploration, 177: 45-60.

Fontana, E., Renac, C., Mexias, A.S., Barats, A., Gerbe, M.C., Lopes, R.W. \& Nardi, L.V.S. 2019. Mass balance and origin of fluids associated to smectite and chlorite/smectite alteration in Seival Mine Cu-Mineralization - Camaquã Basin - Brazil (Part II). Journal of Geochemical Exploration, 196: 20-32.

Fragoso Cesar, A.R.S., Fambrini, G.L., Almeida, R.P., Pelosi, A.P.M.R., Janikian, L., Riccomini, C., Machado, R., Nogueira, A.C.R. \& Saes, G.S. 2000. The Camaquã extensional basin: Neoproterozoic to early Cambrian sequences in southernmost Brazil. Revista Brasileira de Geociências, 30(3): 442-445.

Gastal, M.C.P., Ferreira, F.J.F., Cunha, J.U., Esmeris, C., Koester, E., Raposo, M.I.B \& Rosseti, M.M.M. 2015. Alojamento do granito Lavras e a mineralização aurífera durante evolução de centro Vulcano-plutônico pós-colisional, oeste do Escudo Sul-riograndense: dados geofísicos e estruturais. Brazilian Journal of Geology, 45(2): 217-241.

Graettinger, A.H. 2018. Trends in maar crater size and shape using the global Maar Volcano Location and Shape (MaarVLS) database. Journal of Volcanology and Geothermal Research, 357: 1-13.

Green, J. \& Short, N.M. 1971. Volcanic landforms and surface features - a photographic atlas. Berlin, Springer-Verlag, 519p.

Hasui, Y., Carneiro, C.D.R. \& Coimbra, A.W., 1975. The Ribeira folded belt. Revista Brasileira de Geociências, 5: 257-266.

Jerram, D. \& Petford, N. 2011. Field description of igneous rocks. $2^{\text {nd }}$ ed., Hoboken, WileyBlackwell, $258 \mathrm{p}$.

Lima, E.F. \& Nardi, L.V.S. 1998. The Lavras do Sul Shoshonitic Association: implications for the origin and evolution of Neoproterozoic shoshonitic magmatism in southernmost Brazil. Journal of South American Earth Sciences, 11(1): 67-77.

Lima, E.F., Sommer, C.A. \& Nardi, L.V.S. $2007 a$. O vulcanismo Neoproterozóico-Ordoviciano no Escudo Sul-Riograndense: os ciclos vulcânicos da Bacia do Camaquã. In: Iannuzzi, 
R. \& Frantz, J. C. (Ed.). 50 anos de Geologia: Instituto de Geociências. Contribuições. Porto Alegre, Comunicação e Identidade, p. 79-97.

Lima, E.F., Nardi, L.V.S. \& Sommer, C.A., 2007b. Lamprófiros espessartíticos da Associação Shoshonítica de Lavras do Sul-RS: litoquímica e química mineral. In: Iannuzzi, R. \& Frantz, J. C. (Eds). 50 anos de Geologia: Instituto de Geociências. Contribuições. Porto Alegre: Comunicação e Identidade, p. 43-58.

Liz, J.D., Lima, E.F., Nardi, L.V.S., Hartmann, L.A., Sommer, C.A. \& Gonçalves, C.R.H. 2004. Aspectos petrográficos e composicionais do sistema multi-intrusivo da Associação Shoshonítica de Lavras do Sul (RS) e seu potencial para mineralizações de ouro e sulfetos. Revista Brasileira de Geociências, 34(4): 539-552.

Lopes, R.W., Fontana, E., Mexias, A.S., Gomes, M.E.B., Nardi, L.V.S. \& Renac, C. 2014. Caracterização petrográfica e geoquímica da sequência magmática da Mina do Seival, Formação Hilário (Bacia do Camaquã Neoproterozoico), Rio Grande do Sul, Brasil. Pesquisas em Geociências, 41(1): 51-64.

Lopes, R.W., Mexias, A.S., Philipp, R.P., Bongiolo, E.M., Renac, C., Bicca, M.M. \& Fontana, E. 2018. Au-Cu Ag mineralization controlled by brittle structures in Lavras do Sul Mining District and Seival Mine deposits, Camaquã Basin, southern Brazil. Journal of South American Earth Sciences, 88: 197-215.

Lopes, R.W., Renac, C., Mexias, A.S., Nardi, L.V.S., Fontana, E., Gomes, M.E.B. \& Barats, A. 2019. Mineral assemblages and temperature associated with $\mathrm{Cu}$ enrichment in the Seival área (Neoproterozoic Camaquã Basin of southern Brazil). Journal of Geochemical Exploration, 201: 56-70.

Lorenz, V. \& Kurszlaukis, S. 2006. Root zone processes in the phreatomagmatic pipe emplacement model and consequences for the evolution of maar-diatreme volcanoes. Journal of Volcanology and Geothermal Research, 159: 4-32.

Martins, J.A., Castro, N.A. \& Castelo Branco, R.M.G. 2016. A morfologia superficial da estrutura circular de São Miguel do Tapuio (Piauí-BR) e casos similares no território brasileiro. Geociências, 35(2): 183-202.

Müller, I.F., Nardi, L.V.S., Lima, E.F. \& Mexias, A.S. 2012. Os diques latíticos portadores de ouro e sulfetos da Associação Shoshonítica de Lavras do Sul - RS: petrogênese e geoquímica. Pesquisas em Geociências, 39(2): 173-191.

Mundula, F., Cioni, R., Funedda, A. \& Leone, F. 2013. Lithofacies characteristics of diatreme deposits: examples from a basaltic volcanic field of SW Sardinia (Italy). Journal of Volcanology and Geothermal Research, 255: 1-14.

Nardi, L.V.S. \& Lima, E.F. 1985. A Associação Shoshonítica de Lavras do Sul, RS. Revista Brasileira de Geociências, 15(2):139-146.

Nardi, L.V.S. \& Lima, E.F. 1988. Hidrotermalismo no Complexo Granítico Lavras e vulcânicas associadas, RS. Revista Brasileira de Geociências, 18(3): 369-375.

Nasir, S., Al-Khirbash, S., Rollinson, H., AlHarthy, A., Al-Sayigh, A., Al-Lazki, A., Theye, T., Massone, H.-J. \& Belousova, E. 2011. Petrogenesis of early cretaceous carbonatite and ultramafic lamprophyres in a diatreme in the Batain Nappes, Eastern Oman continental margin. Contributions to Mineralogy and Petrology, 161: 47-74.

Oliveira, C.H.E., Chemale Jr., F., Jelinek, A.R., Bicca, M.M. \& Philipp, R.P. 2014. U-Pb and $\mathrm{Lu}-\mathrm{Hf}$ isotopes applied to the evolution of the late to post-orogenic transtensional basins of the Dom Feliciano Belt, Brazil. Precambrian Research, 246: 240-255.

Paim, P.S.G., Chemale Jr., F. \& Lopes, R.C. 2000. A Bacia do Camaquã. In: Holz, M. \& De Ros, L.F. (Ed.). Geologia do Rio Grande do Sul. Porto Alegre, CIGO/UFRGS, p. 231-274.

Paim, P.S.G., Chemale Jr., F.C. \& Wildner, W. 2014. Estágios evolutivos da Bacia do Camaquã (RS). Ciência e Natura, 36: 183-193.

Palladino, D.M., Valentine, G.A., Sottili, G. \& Taddeucci, J. 2015. Maars to calderas: endmembers on a spectrum of explosive volcanic depressions. Frontiers in Earth Science, 3: 36.

Philipp, R.P. \& Machado, R. 2005. The late Neoproterozoic granitoid magmatism of Pelotas Batholith, southern Brazil. Journal of South American Earth Sciences, 19: 461-478. Philipp, R.P., Pimentel, M.M. \& Basei, M.A.S. 
2018. The Tectonic Evolution of the São Gabriel Terrane, Dom Feliciano Belt, Southern Brazil: The Closure of the Charrua Ocean. In: S. Siegesmund et al. (eds.). Geology of Southwest Gondwana - Regional Geology Reviews. Berlin, Springer-Verlag, p. 243-266.

Ramos, R.C., Koester, E. \& Vieira, D.T. 2019. Plagioclase-hornblende geothermobarometry of metamafites from the Arroio Grande Ophiolite, Dom Feliciano Belt, southernmost Brazil. Journal of South American Earth Sciences, 95: 102262.

Reischl, J.L. 1978. Mineralizações cupriferas associadas a vulcânicas na Mina do Seival. In: XXX CONGRESSO BRASILEIRO DE GEOLOGIA, 1978, Recife. Anais... SBG. v. 4, p. 1568-1582.

Ribeiro, M. \& Fantinel, L.M. 1978. Associacões petrotectônicas do Escudo Sul-Riograndense: | Tabulação e distribuicão das associações petrotectônicas do Escudo do Rio Grande do Sul. Inheringia Serviço Geológico, 5: 19-54.

Satian, M. A., Sahakyan, L. H. \& Stepanyan, Z. O. 2009. Composition of Tuffs from Lamprophyre Diatremes of the Vedi Rift, Armenia. Lithology and Mineral Resources, 44(4): 399-409.

Toniolo, J.A., Gil, C.A.A. \& Sander, A. 2007. Metalogenia das Bacias NeoproterozoicoEopaleozoicas do Sul do Brasil - Bacia do Camaquã. Porto Alegre, CPRM, 154p.

Tratz, E.B. \& Waichel, B.L. 2019. Variações no padrão de relevo associadas aos diferentes derrames e formas vulcânicas preservadas na porção central da Província Magmática do Paraná-Etendeka. Revista GeoUECE, 8(15): 178-192.

White, J.D.L. \& Ross, P.-S., 2011. Maar-diatreme volcanoes: a review. Journal of Volcanology and Geothermal Research, 201: 1-29.

Wildner, W., Lima, E.F., Nardi, L.V.S. \& Sommer, C.A., 2002. Volcanic cycles and setting in the Neoproterozoic III to Ordovician Camaquã Basin succession in southern Brazil: characteristics of post-collisional magmatism. Journal of Volcanology and Geothermal Research, 118: 261-283. 